Glu 122, are involved in catalysis.

\section{Methods}

Sample preparation. The DNA encoding residues $47-210$ of tGCN5 was amplified from the $\mathrm{CDNA}^{1}$ and subcloned into the NdeI-HindIII site of the pRSET-B vector (Invitrogen). Nine TAA and TAG codons, which encode glutamine in Tetrahymena, were mutated to CAA and CAG and verified by DNA sequencing. Phe 90 (encoded by TTT) was mistakenly identified as Leu (encoded by CTT) in the sequence published previously ${ }^{1}$. The protein was expressed in Escherichia coli strain BL21(DE3) in LB or M9 medium with appropriately enriched $\mathrm{NH}_{4} \mathrm{Cl}$ and glucose and appropriate $\mathrm{D}_{2} \mathrm{O} / \mathrm{H}_{2} \mathrm{O}$ ratios. NMR samples contained $0.4-0.5 \mathrm{mM}$ protein in $\left(50 \mathrm{mM} \mathrm{NaH}{ }_{2} \mathrm{PO}_{4} / \mathrm{Na}_{2} \mathrm{HPO}_{4}\right.$ pH $6.5,100 \mathrm{mM} \mathrm{NaCl}, 10 \mathrm{mM}$ DTT, $0.8-1.0 \mathrm{mM}$ unlabelled CoA, $0.1 \mathrm{mM}$ $\mathrm{NaN}_{3}, 0.1 \mathrm{mM}$ EDTA)

NMR spectroscopy. NMR spectra were acquired at $27^{\circ} \mathrm{C}$. We obtained protein backbone assignments from triple resonance spectra of $100 \%{ }^{2} \mathrm{H}-,{ }^{15} \mathrm{~N}-$ and ${ }^{13} \mathrm{C}$-labelled samples as described ${ }^{17} . \mathrm{H}^{\alpha}$ protons were assigned from a $3 \mathrm{D}$ ${ }^{15} \mathrm{~N}$ TOCSY-HSQC spectrum. Almost complete side-chain resonances were assigned using $\mathrm{H}(\mathrm{CC})(\mathrm{CO}) \mathrm{NH}$ and $(\mathrm{H}) \mathrm{C}(\mathrm{C})(\mathrm{CO}) \mathrm{NH}$ spectra of a $65 \%{ }^{2} \mathrm{H}$, $100 \%{ }^{15} \mathrm{~N}$ - and ${ }^{13} \mathrm{C}$-labelled sample and a ${ }^{13} \mathrm{C}$ NOESY-HSQC spectrum ${ }^{19}$. The CoA protons were assigned from 2D TOCSY and 2D NOESY spectra of a $100 \%$ ${ }^{2} \mathrm{H}$-labelled sample in $\mathrm{D}_{2} \mathrm{O}$. Intramolecular distance restraints were obtained using ${ }^{15} \mathrm{~N}$ NOESY-HSQC, ${ }^{13} \mathrm{C}$ NOESY-HSQC and 2D NOESY spectra. Intermolecular restraints were obtained from a $2 \mathrm{D}{ }^{15} \mathrm{~N}$ NOESY-HSQC spectrum of a $100 \%{ }^{2} \mathrm{H}$ - and ${ }^{15} \mathrm{~N}$-labelled sample and a $2 \mathrm{D}{ }^{13} \mathrm{C}$-edited ${ }^{12} \mathrm{C}$-filtered NOESY spectrum of a $100 \%{ }^{15} \mathrm{~N}$ - and ${ }^{13} \mathrm{C}$-labelled sample.

Structure calculation. We derived distance restraints as described ${ }^{18}$. There were 2248 intra-protein NOE-derived restraints (1139 intra-residue, 512 sequential, 214 medium range, and 382 long range), 58 intra-protein hydrogen bond restraints for slowly exchanging backbone amide protons in regular secondary structure, 37 intra-CoA restraints and 54 intermolecular restraints. No dihedral angle restraints were used. Structures were calculated using a twostage protocol ${ }^{17}$, adding the $\mathrm{CoA}$ in a random conformation and orientation for the second stage. Forty-nine out of 60 starting structures were selected after the first stage and 35 out of 49 structures after the second stage, on the basis of small total X-PLOR energies. An additional 10 structures were discarded because the CoA adenine group had a conformation that was not consistent with the NOE data. The final 25 structures have no NOE violations greater than $0.4 \AA$, and $93.7 \%$ of the non-glycine and non-proline residues lie in the most favourable and additionally allowed regions of the Ramachandran plot. The mean r.m.s. deviation from the mean structure is $0.54 \pm 0.102 \AA$ for the backbone heavy atoms of residues $49-176$ and 196-203,1.10 $\pm 0.108 \AA$ for all heavy atoms of the same residues, and $0.59 \pm 0.12 \AA$ for all heavy atoms of CoA. The r.m.s. deviations from ideal geometry are $0.0030 \AA$ for bonds, $0.48^{\circ}$ for bond angles and $0.34^{\circ}$ for improper angles. Figures were produced with InsightII program (Molecular Simulations Inc., San Diego) (Fig. 1b), Molscript ${ }^{20}$ (Fig. 1c), and GRASP $^{21}$ (Fig. 3).

Histone peptide titrations. We performed histone peptide titrations with $0.25-\mathrm{mM}$ samples of ${ }^{15} \mathrm{~N}$-labelled protein, recording ${ }^{15} \mathrm{~N}$ HSQC spectra before and after addition of the unlabelled histone $\mathrm{H} 3$ peptides (1)-ARTKQTARKSTGGKAPRKQLQ-(21) and (9)-KSTGGKAPRKQ-(19) at concentrations of up to 1.3 and $1.0 \mathrm{mM}$, respectively.

Received 16 February; accepted 12 May 1999.

1. Brownell, J. E. et al. Tetrahymena histone acetyltransferase A: a homolog to yeast Gen5p linking histone acetylation to gene activation. Cell 84, 843-851 (1996).

2. Kuo, M. H., Zhou, J., Jambeck, P., Churchill, M. E. A. \& Allis, C. D. Histone acetyltransferase activity of yeast Gcn5p is required for the activation of target genes in vivo. Genes Dev. 12, 627-639 (1998).

3. Wang, L. et al. Histone acetyltransferase activity is conserved between yeast and human GCN5 and is required for complementation of growth and transcriptional activation. Mol. Cell. Biol. 17, 519-527 (1997).

4. Bannister, A. J. \& Kouzarides, T. The CBP co-activator is a histone acetyltransferase. Nature 384, 641 643 (1996)

Grant, P. A. et al. A subset of TAF(II)s are integral components of the SAGA complex required for nucleosome acetylation and transcriptional stimulation. Cell 94, 45-53 (1998).

6. Mizzen, C. A. et al. The TAF(II) 250 subunit of TFIID has histone acetyltransferase activity. Cell 87 , 1261-1270 (1996)

Ogryzko, V. V., Schiltz, R. L., Russanova, V., Howard, B. H. \& Nakatani, Y. The transcriptiona coactivators p300 and CBP are histone acetyltransferases. Cell 87, 953-959 (1996).

8. Ogryzko, V. V. et al. Histone-like TAFs within the PCAF histone acetylase complex. Cell 94, 35-44 (1998).

9. Yang, X. J., Ogryzko, V. V., Nishikawa, J., Howard, B. H. \& Nakatani, Y. A p300/CBP-associated factor that competes with the adenoviral oncoprotein E1A. Nature 382, 319-324 (1996).
10. Wolf, E. et al. Crystal structure of a GCN5-related N-acetyltransferase: Serratia marcescens aminoglycoside 3-N-acetyltransferase. Cell 94, 439-449 (1998).

11. Dutnall, R. N., Tafrov, S. T., Sternglanz, R. \& Ramakrishnan, V. Structure of the histone acetyltransferase Hat1: a paradigm for the GCN5-related N-acetyltransferase superfamily. Cell 94, 427-438 (1998).

12. Candau, R., Zhou, J. X., Allis, C. D. \& Berger, S. L. Histone acetyltransferase activity and interaction with ADA2 are critical for GCN5 function in vivo. EMBO J. 16, 555-565 (1997).

13. Neuwald, A. F. \& Landsman, D. GCN5-related histone N-acetyltransferases belong to a diverse superfamily that includes the yeast SPT10 protein. Trends Biochem. Sci. 22, 154-155 (1997).

14. Tanner, K. G. et al. Catalytic mechanism and function of invariant glutamic acid-173 from the histone acetyltransferase GCN5 transcriptional activator. J. Biol. Chem. 274, 18157-18160 (1999).

15. Bhatnagar, R. S. et al. Structure of N-myristoyltransferase with bound myristoyl-CoA and peptide substrate analogs. Nature Struct. Biol. 5, 1091-1097 (1998).

16. Parthun, M. R., Widom, J. \& Gottschling, D. E. The major cytoplasmic histone acetyltransferase in yeast: links to chromatin replication and histone metabolism. Cell 87, 85-94 (1996).

17. Matsuo, H. et al. Structure of translation factor eIF4E bound to $\mathrm{m}^{7} \mathrm{GDP}$ and interaction with $4 \mathrm{E}-$ binding protein. Nature Struct. Biol. 4, 717-724 (1997).

18. Fletcher, C. M., Pestova, T. V., Hellen, C. U. T. \& Wagner, G. Structure and interactions of the translation initiation factor eIF1. EMBO J. 18, 2631-2637 (1999).

19. Lin, Y. \& Wagner, G. Efficient side chain and backbone assignments in large proteins. J. Am. Chem. Soc. (submitted).

20. Kraulis, P. J. MOLSCRIPT: a program to produce both detailed and schematic plots of protein structures. J. Appl. Crystallogr. 24, 946-950 (1991).

21. Nicholls, A., Sharp, K. A. \& Honig, B. Protein folding and association: insights from the interfacial and thermodynamic properties of hydrocarbons. Proteins 11, 281-296 (1991)

Acknowledgements. We thank R. Marmorstein for initiating this work and providing the histone peptides; G. Heffron for help with NMR experiments; V. Ramakrishnan for providing the coordinates of $\mathrm{yHat} 1$ before their release by the PDB; and J. Denu for providing a copy of his paper before publication. This project was supported by grants from NSF, NIH, the Harvard Center for Structural Biology and the Giovanni Armenise-Harvard Foundation for Advanced Scientific Research.

Correspondence and requests for materials should be addressed to G.W. (e-mail: wagner@wagner.med. harvard.edu). Atomic coordinates have been deposited in the Protein Data Bank, accession code 5GCN.

\section{erratum}

\section{The CED-4-homologous protein FLASH is involved in Fas-mediated activation of caspase-8 during apoptosis}

\section{Yuzuru Imai, Takaharu Kimura, Akira Murakami, Nobuyuki Yajima, Kazuhiro Sakamaki \& Shin Yonehara}

Nature 398, 777-785 (1999)

In this Article, the GenBank accession number of the nucleotide sequence of mouse FLASH was deleted. The accession number is AF132726.

\section{correction}

Structural basis for initiation of transcription from an RNA polymerase-promoter complex

\section{Graham M. T. Cheetham, David Jeruzalmi \& Thomas A. Steitz}

Nature 399, 80-83 (1999)

The accession number of the coordinates deposited in the Protein Data Bank was wrongly given as 1ClZ: the correct accession number is 1CEZ. 


\title{
The CED-4-homologous protein FLASH is involved in Fas-mediated activation of caspase-8 during apoptosis
}

\author{
Yuzuru Imai, Takaharu Kimura, Akira Murakami, Nobuyuki Yajima, Kazuhiro Sakamaki \& Shin Yonehara \\ Institute for Virus Research, Kyoto University, Shogoin, Sakyo-ku, Kyoto 606-8507, Japan
}

Fas is a cell-surface receptor molecule that relays apoptotic (cell death) signals into cells. When Fas is activated by binding of its ligand, the proteolytic protein caspase-8 is recruited to a signalling complex known as DISC by binding to a Fas-associated adapter protein. A large new protein, FLASH, has now been identified by cloning of its complementary DNA. This protein contains a motif with oligomerizing activity whose sequence is similar to that of the Caenorhabditis elegans protein CED-4, and another domain (DRD domain) that interacts with a death-effector domain in caspase-8 or in the adapter protein. Stimulated Fas binds FLASH, so FLASH is probably a component of the DISC signalling complex. Transient expression of FLASH activates caspase-8, whereas overexpression of a truncated form of FLASH containing only one of its DRD or CED-4-Iike domains does not allow activation of caspase-8 and Fas-mediated apoptosis to occur. Overexpression of full-length FLASH blocks the anti-apoptotic effect of the adenovirus protein E1B 19K. FLASH is therefore necessary for the activation of caspase-8 in Fas-mediated apoptosis.

Fas is a widely expressed cell-surface receptor molecule belonging to the tumour-necrosis factor (TNF) receptor family ${ }^{1,2}$, which can induce apoptotic signals in Fas-expressing cells by binding with agonistic anti-Fas monoclonal antibody or with its natural ligand, FasL (CD95L) $)^{3-5}$. The mechanism of signal transduction of Fasmediated apoptosis has been extensively investigated as a model of mammalian apoptotic cell death. Several proteins have been identified that bind the intracellular domain of Fas, designated the death domain, which is essential for signal transduction of Fas-mediated apoptosis $^{2}$. Of the Fas-binding molecules, the adapter protein FADD/MORT1, which has a death domain in its carboxy-terminal region, has an important function in Fas-mediated apoptosis ${ }^{6-9}$. FADD is recruited to Fas after stimulation of Fas ${ }^{10}$, and then binds caspase-8 (also known as FLICE/MACH/Mch5), a member of the mammalian caspase family through homophilic interaction between the amino-terminal domains of FADD and caspase-8, which are known as the death-effector domains (DED) ${ }^{11,12}$. In the complex of Fas, FADD and caspase- 8 , which is called the deathinducing signalling complex (DISC) ${ }^{10}$, caspase- 8 becomes proteolytically autoactivated by oligomerization ${ }^{13,14}$, whereupon it stimulates other caspases, including caspases 3 (ref. 15), 6 (ref. 16) and 7 (ref. 17), by cleaving them. These downstream caspases cleave the death substrates ${ }^{18}$ that are central to apoptotic events such as morphological changes ${ }^{19}$ and DNA fragmentation ${ }^{20}$.

Although it has been proposed that caspase- 8 is proteolytically autoactivated in the DISC complex after oligomerization through its DED domain during Fas-mediated apoptosis ${ }^{13,14}$, we suspected that some other molecule(s) apart from Fas and FADD could activate caspase- 8 in DISC; this was based on the fact that the Caenorhabditis elegans protein CED-4 and its mammalian homologue Apaf-1 are required for the activation of $C$. elegans caspase CED-3 and mammalian caspase-9, respectively ${ }^{21,22}$. It has been shown that the anti-apoptotic adenovirus protein E1B19K, which is unable to bind Fas, FADD or caspase-8, can indirectly prevent Fas-mediated and FADD-induced activation of caspase-8 (ref. 23), indicating that it may inhibit Fas-mediated apoptosis by binding an unknown protein(s) that is involved in the activation of caspase- 8 . In addition, Fas-induced DISC formation was barely detectable in some Fas-sensitive cells expressing sufficient amounts of the known components of $\mathrm{DISC}^{24}$, suggesting that there may be another component(s) in the DISC. Here we identify a new protein that binds to caspase-8, which we call FLASH (for 'FLICE-associated huge' protein). We show that FLASH, which contains a motif structurally related to CED-4/Apaf-1 and two tandem-repeated DED homologous domains, is required for the activation of caspase- 8 during Fas-mediated apoptosis.

\section{Identification of FLASH}

To investigate the mechanism of activation of caspase- 8 in Fasmediated apoptosis, we screened a mouse T-cell complementary DNA library by using the yeast two-hybrid technique and two tandem-repeated DED domains of procaspase- 8 as a probe. We obtained $76 \beta$-galactosidase-positive clones from $2 \times 10^{7}$ library transformants. Classification of the positive clones by restriction analysis and nucleotide sequencing revealed that they contained thirteen independent clones of FADD, seven UBC9 clones, two cFLIP/Casper/CASH short forms, and two other unknown clones, numbers 68 and 149. UBC9, which is one of the ubiquitinconjugating enzymes (E2), binds Fas or other molecules in yeast two-hybrid experiments. A BLAST search suggested that clone 68 was a mouse homologue of Gal4. The other clone, clone 149, has no significant identity to any proteins in the GenBank Database but has a domain homologous to DED of caspase- 8 .

To obtain the full-length sequence of clone 149, rapid amplification of 5' cDNA ends by polymerase chain reaction (5'-RACE PCR) was performed using a cDNA library from WR19L12a cells, and then a cDNA library prepared from F9 cells was screened by colony hybridization with the fragments obtained by $5^{\prime}$-RACE PCR. Partially overlapping isolated inserts were ligated to give a cDNA containing a very long open reading frame (5,886 base pairs (bp)) with an initiator methionine (ACCATGG), in agreement with Kozak's consensus ${ }^{25}$. We determined the initiation site by finding an in-frame stop codon $18 \mathrm{bp}$ upstream of the putative initiator methionine in a $\mathrm{G}+\mathrm{C}$-rich $5^{\prime}$ region of the $\mathrm{CDNA}$. This gene encodes FLASH, a polypeptide of 1,962 amino-acid residues and of predicted relative molecular mass $219.1 \mathrm{~K}$ (Fig. 1a). 


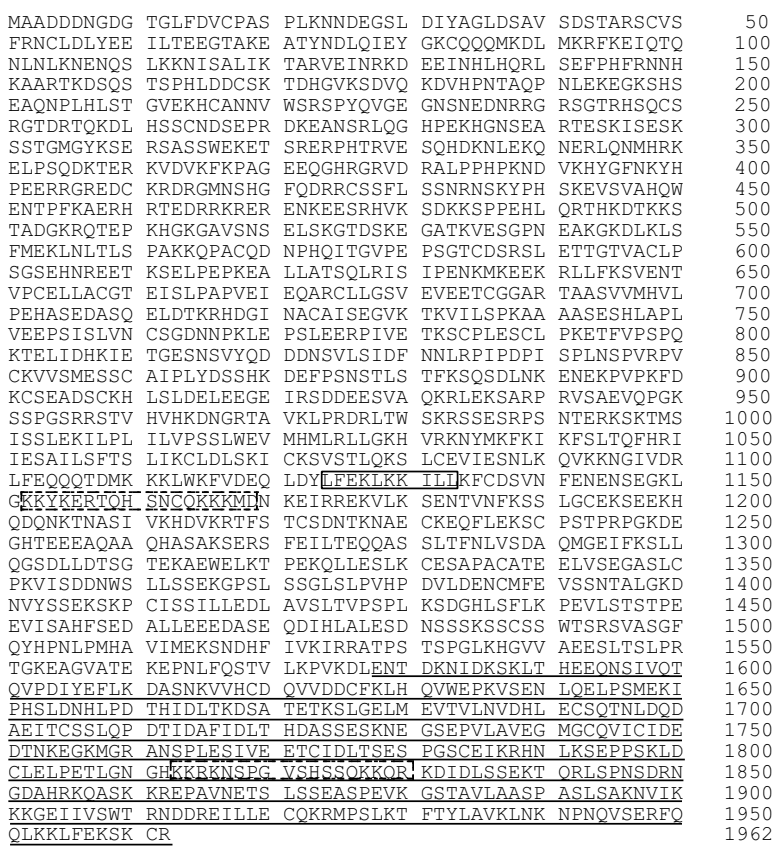

b

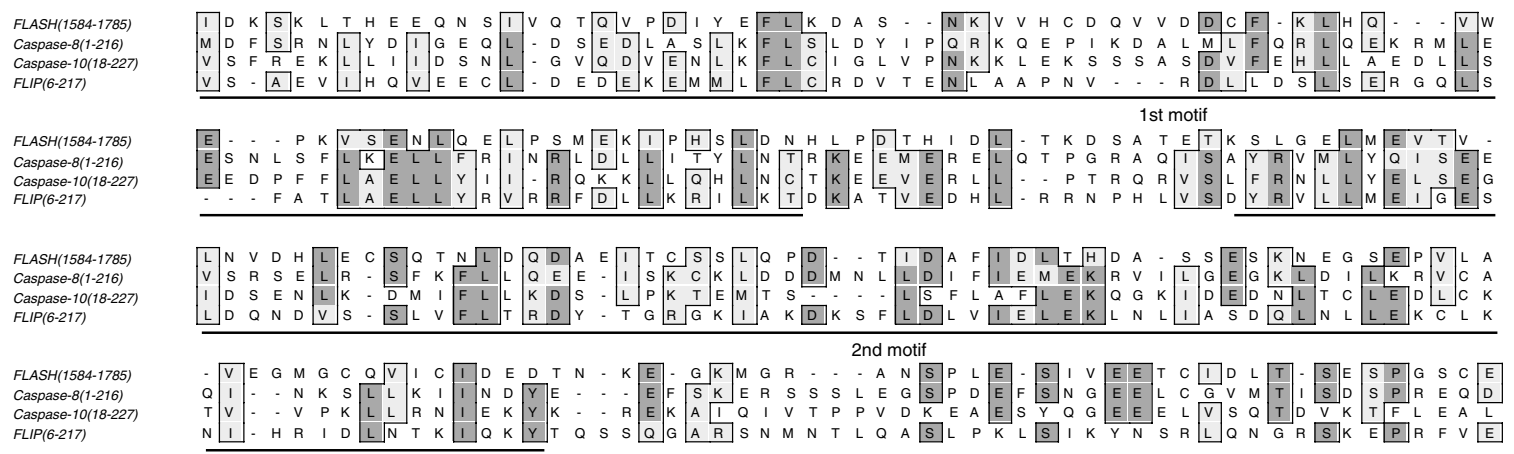

Figure 1 Structure of mouse FLASH and sequence comparison. a, The deduced amino-acid sequence of mouse FLASH. Numbers on the right indicate the aminoacid residue position. The original clone isolated by yeast two-hybrid screening is underlined. The box and dotted boxes indicate the putative nuclear exclusion signal (NES) and the putative nuclear localization signal (NLS), respectively. b. Sequence alignment of amino-acid residues 1,584-1,785 of FLASH (DRD) with the two tandem-repeated DED of caspase-8, -10, and c-FLIP. Dark shaded boxes, identical residues; light shaded boxes, similar residues. The first and second
Sequence analysis of FLASH revealed that the C-terminal region originally obtained from a yeast expression library contained a domain significantly homologous to the duplicated DED of caspase- 8 (sequence was $20 \%$ identical and $41 \%$ similar), although the similarity of the duplicated DED of caspase- 8 to FLASH is less than that to c-FLIP and caspase-10 (Fig. 1b). Some consensus amino-acid residues in DED are not conserved in FLASH. We designated this DED-like domain of FLASH as DRD (for DEDrecruiting domain), because FLASH interacts with the DED domain not only of caspase- 8 but also of FADD through its DED-like domain (see later).

An ATP/GTP-binding motif homologous to the Walker's A-box consensus sequence was found in the central part of FLASH (amino acids 944-951; underlined in Fig. 1c) ${ }^{26}$. The region at residue positions 939-1,191 containing the putative nucleotide-binding site showed weak structural similarity with CED-4, Apaf-1, tomato PRF and plant resistance-gene products (Fig. 1c). This region of FLASH, however, contains an extra stretch of 24 amino-acid residues at 1,030-1,054 as compared with other CED-4-homologous proteins, and appears to lack the Walker's B-box (Fig. 1c). The sequence identity and similarity between the region of FLASH before the insert (residues 939-1,029) and the corresponding region of CED-4 were 18 and 38\%, respectively. Those between the region of FLASH after the insert (amino acids 1,055-1,191) and the corresponding region of CED-4 were 15 and 33\%, respectively. The amino-terminal segment of FLASH (residues 1-858; region $\Delta \mathrm{A}$ in Fig. 1d) showed no significant homology to any protein in the GenBank Database.

We found an amino-acid sequence homologous to the nuclearlocalization signal (NLS) in the C-terminal region of $\mathrm{FLASH}^{27}$ and a nuclear-exclusion signal (NES)-like sequence ${ }^{28}$ in the central region of FLASH (LFEKLKKILL) (Fig. 1a). The putative NES of FLASH may be functional because western blotting with rabbit anti-FLASH antibody indicates that most FLASH is in the cytoplasmic fraction (data not shown).

Northern blotting analysis revealed that FLASH was constitutively expressed as two transcripts (of $\sim 4.7 \mathrm{~kb}$ and $\sim 7 \mathrm{~kb}$ ) in all adult mouse tissues examined (Fig. 2). Its expression was relatively high in the heart, brain, thymus, lung, testis (Fig. 2) and spleen (data not shown). Western blotting analysis with an affinity-purified rabbit anti-FLASH antibody detected specific bands at $220 \mathrm{~K}$ in NIH3T3, Balb3T3 and FH2 cells and in mouse thymocytes (data not shown). The relative molecular mass of this band coincided with the value calculated from the deduced amino-acid sequence, indicating 
FLASH (939-1029) CED-4 (154-236) APAF-1 (138-220) PRF (1117-1189) RPP5 (211-285)

FLASH (939-1029) CED-4 (154-236) PRF (1117-1189) RPP5 (211-285)

FLASH (1055-1191) CED-4 (239-374) APAF-1 (221-352) PRF (1192-1338) RPP5 (286-426)

FLASH (1055-1191) CED-4 (239-374) APAF-1 (221-352) PRF (1192-1338) RPP5 (286-426)

FLASH (1055-1191) CED-4 (239-374) APAF-1 (221-352) PRF (1192-1338) RPP5 (286-426)

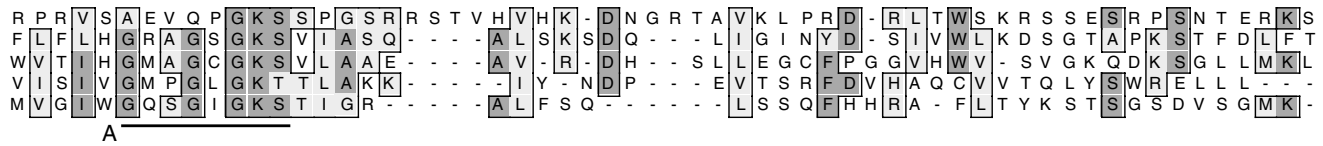

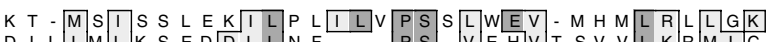

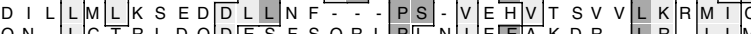
Q N - L L C TR L D Q D E E S F S Q R L P L N I E E A K D R - L R - I L M

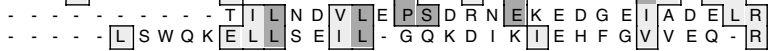

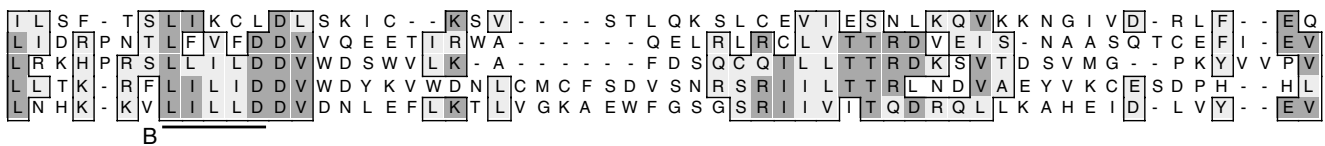

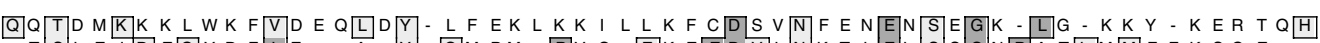

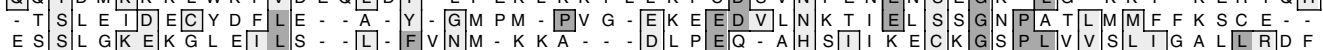

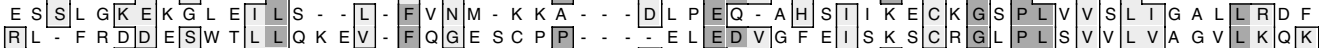

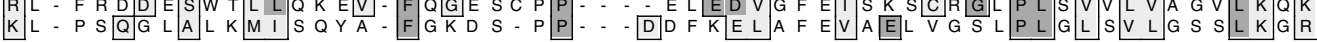

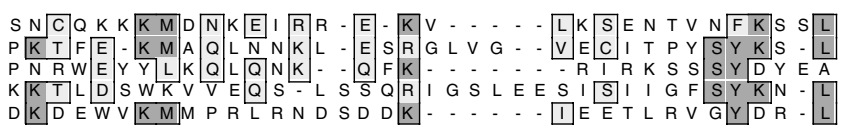

$\begin{array}{lllllllll}K & \\ K & D\end{array}$

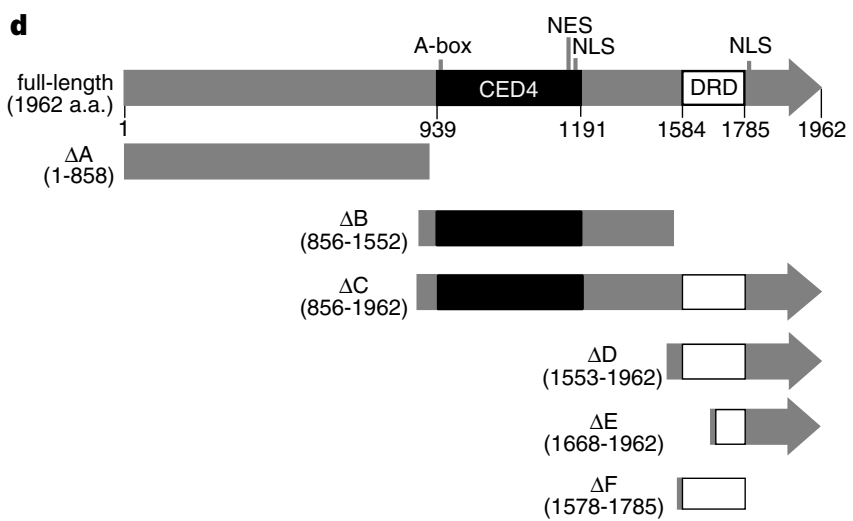

DED or DRD motifs ${ }^{46}$ are underlined. Numbers in parentheses on the left indicate the positions of the first and last residues in the proteins. c, CED-4-homologous domain of FLASH was aligned with the nucleotide-binding and oligomerizing domains of CED-4, Apaf-1, Prf and RPP5 (refs 30, 47). The Walker's A- and B-box

consensus sequences for nucleotide-binding sites are underlined. d, FLASH and its deletion variants. CED-4- and DED-homologous regions, the Walker's A-box consensus motif for the nucleotide-binding site, and the putative NES and NLS are indicated. Numbers refer to amino-acid positions.

that we had isolated the full-length clone of mouse FLASH. The 4.7-kb messenger RNA could encode truncated FLASH, although we could not clone this cDNA by 5 '-RACE PCR and colony hybridization. The significance of this mRNA remains to be determined.

\section{FLASH interacts with caspase-8 and FADD}

To investigate the interaction of FLASH with caspase- 8 in mammalian cells, a Flag-tagged FLASH-expression plasmid (pME18S-FlagFLASH) was used for transient transfection with plasmid for the protease-dead form of procaspase- 8 with a histidine tag (pME18SHis-caspase-8(C360S)) in human 293T cells. His-procaspase8 (C360S) was specifically co-immunoprecipitated with FlagFLASH by an anti-Flag monoclonal antibody (Fig. 3a). The FLASH immunoprecipitate contained the processed N-terminal fragment of caspase-8, p43 (His-p43). As FLASH bound the DED domain of FADD in yeast (data not shown), we tested whether transiently expressed FADD was co-immunoprecipitated with Flag-FLASH in 293T cells. Overexpressed haemagglutinin-tagged (HA)-FADD was found to co-immunoprecipitate with FlagFLASH using anti-Flag mAb (Fig. 3c). FLASH was also shown to bind caspase- 8 and FADD through its DED-like DRD domain:
DRD bound to caspase- 8 and FADD whereas the CED-4-like domain and N-terminal region of FLASH could not bind to these proteins (Fig. 3b, d). Thus, overexpressed FLASH interacts with caspase- 8 and FADD in mammalian cells.

\section{FLASH is a component of DISC}

We analysed the binding of transiently expressed FLASH to endogenous caspase-8, FADD and Fas before and after stimulation of Fas with the agonistic anti-Fas monoclonal antibody CH11 in 293Fas cells (Fig. 3e). Fas and FADD was mainly co-immunoprecipitated with Flag-FLASH only after stimulation of Fas, whereas caspase-8 likewise bound FLASH, regardless of whether Fas was stimulated. These results indicate that FADD and the complex of FLASH with caspase- 8 might be recruited to Fas after stimulation of Fas, and that the association of FLASH and Fas might be indirect.

The formation of DISC, which is composed of at least Fas, FADD and caspase-8, is required for signal transduction of Fas-mediated apoptosis $^{24,29}$. We next tested whether endogenous FLASH could be a component of DISC. Mouse WR19L12a cells stably expressing human Fas were stimulated with $\mathrm{CH} 11$, and then Fas was immunoprecipitated with the anti-Fas monoclonal antibody HFE7A. Consistent with the results of our overexpression experiment, 


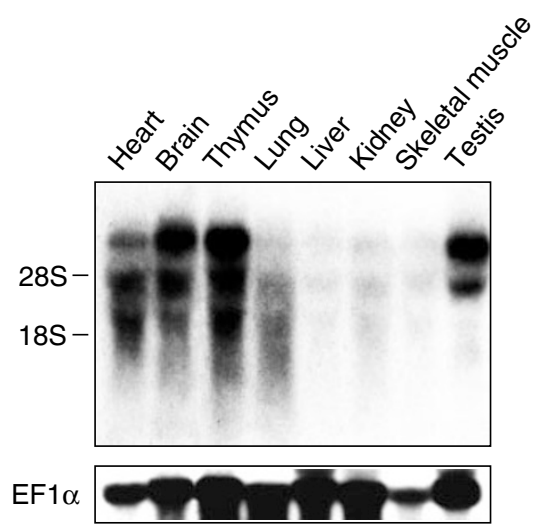

Figure 2 Tissue distribution of mouse FLASH mRNA. Northern blotting analysis has been described ${ }^{43}$. Expression of EF1 $\alpha$ mRNA was used as a standard. endogenous FLASH specifically co-immunoprecipitated with activated Fas (Fig. 4a, lane 3), indicating that FLASH is a component of DISC. The specificity of the anti-FLASH antibody was confirmed by western blotting of a total lysate from 293T cells transfected with or without Flag-FLASH, which showed a specific band at $220 \mathrm{~K}$ (Fig. 4a, lanes 6 and 7). These observations indicate that this antibody can recognize not only transfected mouse FLASH but also human FLASH in 293T cells.

We then analysed DISC formation in two different human cell lines, SKW6.4 and Jurkat. SKW6.4 and Jurkat cells were reported to be type 1 and type II cells, respectively ${ }^{24}$. In type I cells, Fas triggering caused strong caspase- 8 activation at DISC; only a small amount of DISC was formed in type II cells. In type I SKW6.4 cells, DISC consisting of Fas, FADD, caspase- 8 and FLASH was formed after a 5 -min stimulation of Fas (Fig. 4b). There was a weak interaction between Fas and FADD before Fas stimulation, but none between caspase- 8 and Fas. In type II Jurkat cells, which express comparable amounts of DISC components, including FLASH, DISC formation occurred after 5 min of Fas stimulation, although there was much less FADD, FLASH and caspase- 8 co-immunoprecipitating with Fas than in type I cells. These results indicate that FLASH is a component of DISC in both type I and type II cells. a

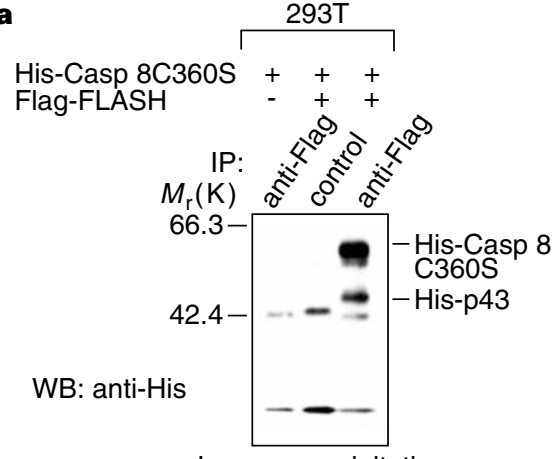

Immunoprecipitation

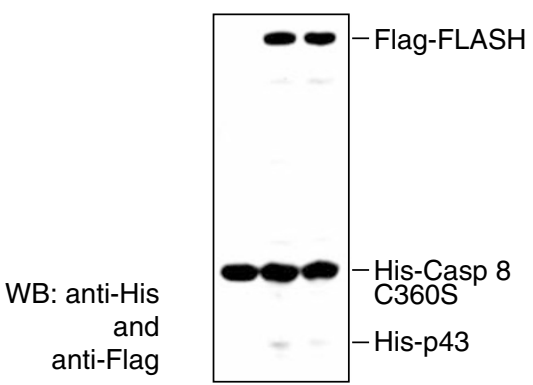

Total lysate b
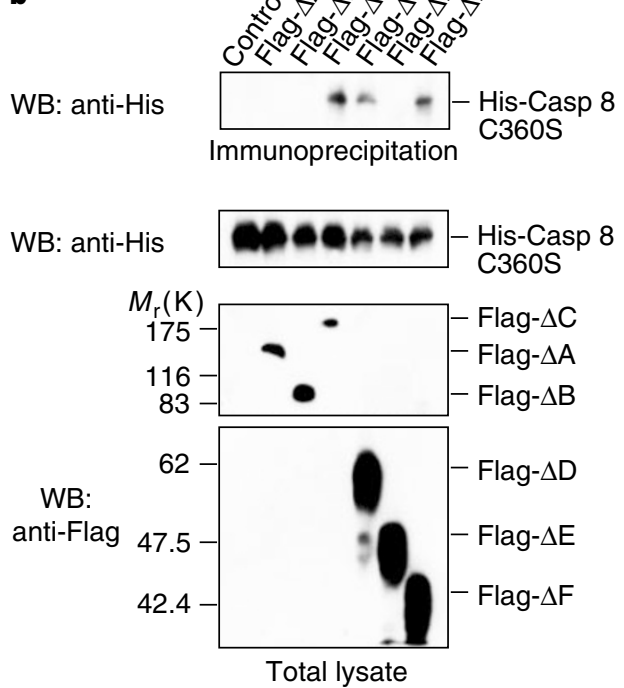

d

anti-HA

anti-HA

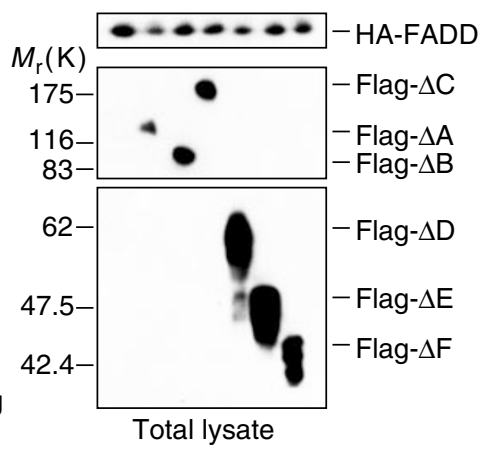

anti-Flag

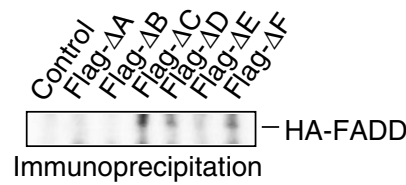

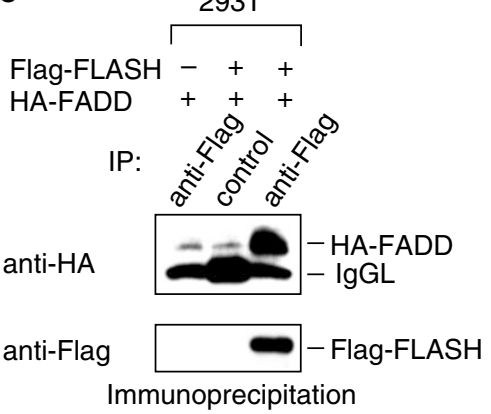

anti-Flag $\quad-$-Flag-FLASH

anti-HA

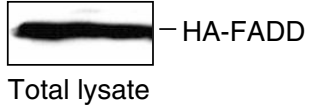

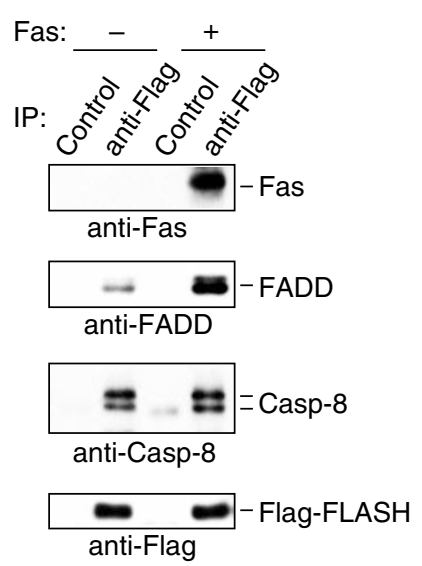

transiently expressed FLASH with endogenous Fas, FADD and caspase-8 in the presence or absence of Fas simulation. See Methods. IP, immunoprecipitation; WB, western blotting.

Figure 3 Overexpressed FLASH interacts with caspase-8, FADD and Fas in mammalian cells. Interaction of FLASH and its deletion variants with caspase-8 (a and b, respectively) and FADD (c and $\mathbf{d}$, respectively). e, Interaction of 


\section{Activation of caspase-8 requires FLASH}

To investigate the function of FLASH, we analysed the effects of transiently transfected FLASH and its deletion mutant on activation of endogenous caspase- 8 by processing in 293Fas cells (Fig. 5a). Expression of FLASH and its mutant was confirmed by western blotting with anti-Flag monoclonal antibody (Fig. 5b, lanes 2 and 3). Immunoblotting with anti-caspase- 8 showed that the active p18 subunit of endogenous caspase- 8 appeared 120 min after stimulation of Fas in control 293Fas cells. The p18 subunit appeared sooner (30 min after stimulation) in 293 Fas cells expressing transfected wild-type FLASH. Overexpression of the truncated $\Delta \mathrm{D}$ mutant of FLASH (comprising amino acids 1,553-1,962; Fig. 1d), which includes the DRD domain, significantly attenuated the production of $\mathrm{p} 18$, although the $\mathrm{p} 43$-cleaved intermediate of caspase- 8 still appeared in cells transfected with $\Delta \mathrm{D}$, as it did with intact FLASH.

We next analysed whether transiently overexpressed FLASH and its mutants (Fig. 1d) could affect Fas-mediated apoptosis in HeLacell-derived HF1 cells stably expressing transfected human Fas (Fig. 5c, f). Overexpression of wild-type FLASH or the $\Delta \mathrm{C}$ FLASH mutant in HF1 cells potentiated Fas-mediated apoptosis after stimulation with anti-Fas antibody, although transfected FLASH and $\Delta \mathrm{C}$ gave no significant effects in the absence of Fas signalling. In contrast, overexpression of either the $\Delta \mathrm{B}$ or $\Delta \mathrm{D}$ mutant inhibited Fas-mediated apoptosis, with co-transfection of $\Delta \mathrm{B}$ and $\Delta \mathrm{D}$ giving the strongest inhibition. Results were similar when 293Fas cells were used instead of HF1 cells (data not shown). In addition, the effects of overexpressed FLASH and its mutants were essentially the same in TNF-mediated apoptosis on HF1 cells, whereas FLASH did not significantly affect staurosporine (STS)induced apoptosis (Fig. 5d, e). Taken together, these results indicate that FLASH, which is recruited to Fas together with caspase- 8 upon stimulation of Fas, is involved in Fas- and TNF-induced apoptosis mediated by activated caspase- 8 , although not in staurosporinemediated apoptosis that may not need caspase-8. In addition, both the DED-like DRD and CED-4-like domains of FLASH are important in Fas- and TNF-induced apoptosis.

\section{Self-association of FLASH}

In C. elegans, CED-4 processes CED-3 by oligomerization, which is inhibited by binding of CED-9 or Bcl- $\mathrm{X}_{\mathrm{L}}$ to CED-4 (ref. 30). These observations raised the possibility that FLASH might activate caspase- 8 in the same way, so we tested whether FLASH could self-associate in vivo. We transfected Flag-tagged FLASH with or without Myc-tagged FLASH into 293T cells, and then immunoprecipitated it with anti-Flag antibody; we found that Myc-FLASH immunoprecipitated with Flag-FLASH (Fig. 6a). Next, four Flagtagged deletion mutants of FLASH were co-expressed with fulllength Myc-FLASH to identify the domain through which FLASH self-associates. Myc-FLASH co-immunoprecipitated with deletion mutant $\Delta \mathrm{B}$, which contains the CED-4-homologous domain, and with $\Delta \mathrm{C}$, which has the CED-4-homologous domain and the DRD domain, but not with the N-terminal $\Delta \mathrm{A}$ mutant, which lacks both, or with the $\mathrm{C}$-terminal $\Delta \mathrm{D}$ mutant containing $\mathrm{DRD}$ (Fig. 6b). These results indicated that FLASH self-associates through the CED-4homologous domain.

\section{Interaction of FLASH with E1B19K}

Although the anti-apoptotic adenovirus protein E1B19K suppresses the activation of caspase- 8 during Fas-mediated and FADDinduced apoptosis ${ }^{23}$, very little is known about how it does this. We therefore tested whether FLASH interacts with E1B19K by overexpressing E1B19K with Flag-FLASH in 293T cells. FlagFLASH was immunoprecipitated with anti-Flag and the co-immunoprecipitated E1B19K was analysed by western blotting (Fig. 7a). We then analysed which domain of FLASH was interacting with E1B19K in 293T cells using our mutants $\Delta \mathrm{A}-\Delta \mathrm{F}$ and found that the
C-terminal region of FLASH $(\Delta \mathrm{D})$, including the DRD domain, could interact with E1B19K (data not shown).

\section{FLASH attenuates the fucntion of E1B19K}

We next tested the effects of FLASH on Fas-mediated apoptosis in FH2 cells transfected with E1B19K and also compared the effects of FLASH on the anti-apoptotic activity of E1B19K and on Z-VADfmk and poxvirus serpin CrmA, which are direct inhibitors of caspase-8 (Fig. 7b). We found that anti-Fas-induced apoptosis was blocked not only by pretreatment with Z-VAD-fmk but also by overexpression of CrmA or E1B19K. Although transiently expressed FLASH did not significantly stimulate Fas-mediated apoptosis in Z-VAD-fmk-treated or CrmA-expressing cells, it significantly inhibited the anti-apoptotic activity of E1B19K in Fas-mediated apoptosis. Essentially similar results were obtained
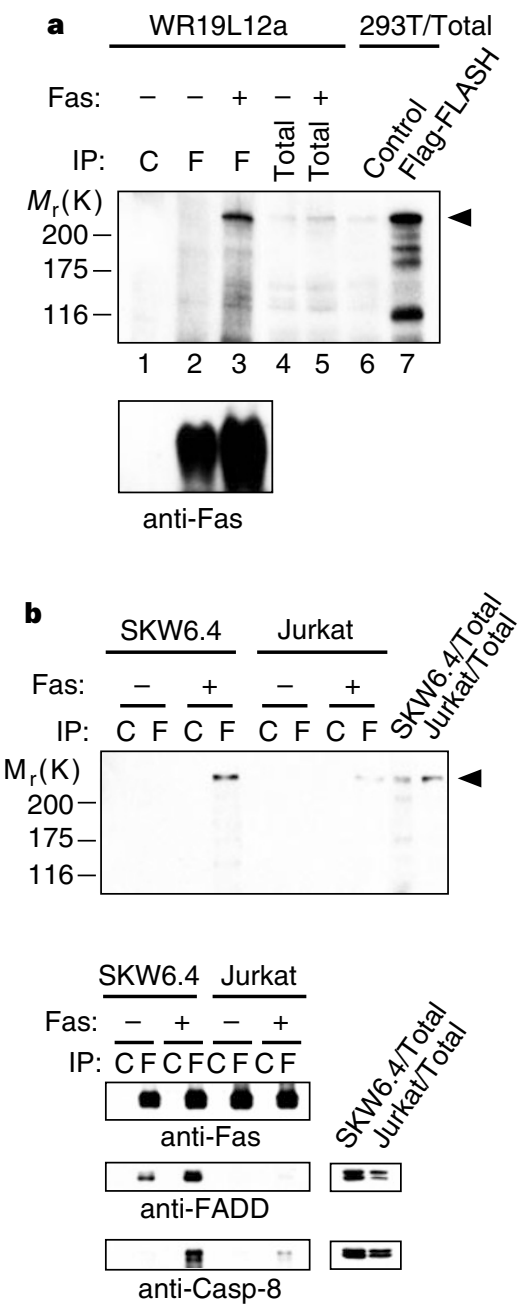

Figure 4 Endogenous FLASH was recruited to activated Fas in mouse WR19L12a and human SKW6.4 and Jurkat cells. a, b. Cells (WR19L12a for a and SKW6.4 and Jurkat for $\mathbf{b}$ ) were treated with $\mathrm{CH} 11$, and immunoprecipitation was performed with HFE7A (F) or control antibody (C). Co-immunoprecipitated endogenous FLASH was detected by western blotting using rabbit anti-FLASH antibody, and immunoprecipitated Fas was also detected using anti-Fas mAb ZB4 (ref. 48) (bottom; lanes 1-3). In $\mathbf{a}$, total lysates of the following cells were analysed by immunoblotting with anti-FLASH antibody: Fas-stimulated (lane 4) and unstimulated (lane 5) WR19L12a cells, and Flag-FLASH-expressing (lane 7) and control (lanes 6) 293T cells. In b, co-immunoprecipitated FADD and caspase-8 in SKW6.4 and Jurkat cells were detected using anti-FADD and anti-caspase-8 monoclonal antibodies. Total lysates of SKW6.4 and Jurkat cells were analysed by immunoblotting with anti-FLASH antibody, anti-FADD and anti-caspase-8 monoclonal antibodies. Arrowheads indicate the position of FLASH. 
when HF1 cells were used instead of FH2 cells, indicating that FLASH links caspase- 8 to E1B19K and E1B19K inhibits the activation of caspase- 8 by binding to FLASH.

\section{Discussion}

Although FLASH associates with Fas and FADD as well as procaspase- 8 in mammalian cells (Figs 3, 4), we do not know whether the association is direct or indirect, or with which protein(s) FLASH prefers to interact under physiological conditions. On the basis of our results from co-immunoprecipitation with and without Fas (Figs 3, 4), FLASH seems to be associated with procaspase- 8 in nonapoptotic mammalian cells. Once Fas signalling is stimulated, FADD and then the FLASH-procaspase- 8 complex are recruited to the intracellular domain of aggregated Fas at the cellular membrane in both SKW6.4 and Jurkat cells (previously reported as type I and type II cells ${ }^{24}$, respectively) (Fig. 4). FLASH may promote the activation of caspase- 8 in DISC with the help of FADD, given that the FLASH mutants $\Delta \mathrm{B}$ and $\Delta \mathrm{D}$ inhibit Fas-mediated activation of caspase- 8 and apoptosis.

Because of the hydrophobicity in the prodomain of procaspase- 8 , this protein is likely to aggregate (Y.I. et al., unpublished observations) and be auto-activated in the cytosol. Overexpression of procaspase- 8 or of the DED domains of caspase- 8 can induce apoptosis. Under physiological conditions, however, the concentra- tion of procaspase- 8 may be too low for it to aggregate and enable DISC to be activated rapidly. CED-4 and Apaf-1, respectively, have been proposed to serve as chaperones to control the local concentrations of CED-3 and procaspase- 9 and to facilitate their autocatalytic activation by inducing conformational changes or oligomerization in response to upstream apoptotic signals. These effects of CED-4 and Apaf-1 are mediated by homophilic interaction between the so-called CARD domains ${ }^{30,31}$. We propose that FLASH may serve as a chaperone to control the conformation and local concentration of procaspase- 8 before the stimulation of Fas; also, FLASH may promote the autocatalytic activity of procaspase- 8 with the help of FADD by binding to procaspase- 8 through DRDDED interaction and oligomerizing procaspase- 8 through its CED4-like domain after activation of Fas (Fig. 6).

FLASH mutants $\Delta \mathrm{B}$ and $\Delta \mathrm{D}$ inhibit Fas-mediated apoptosis in HF1 (Fig. 5c, f) and 293Fas cells (data not shown); they also inhibit TNF-mediated but not staurosporine-induced apoptosis, indicating that FLASH must be required for activation of caspase- 8 . The binding of $\Delta \mathrm{D}$ to procaspase- 8 (Fig. $3 \mathrm{~b}$ ) could prevent it from binding to endogenous FLASH, and $\Delta \mathrm{B}$ may inhibit the oligomerization of endogenous FLASH by binding to it (Fig. 6), so a combination of $\Delta \mathrm{B}$ and $\Delta \mathrm{D}$ caused the strongest inhibition of Fas- and TNF-mediated apoptosis.

More FLASH messenger RNA was expressed in thymocytes (type

a
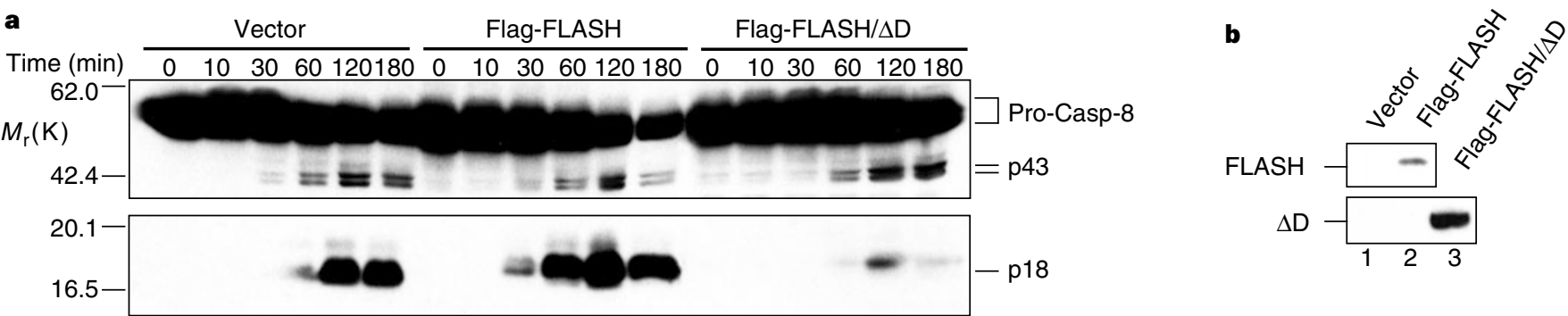

c

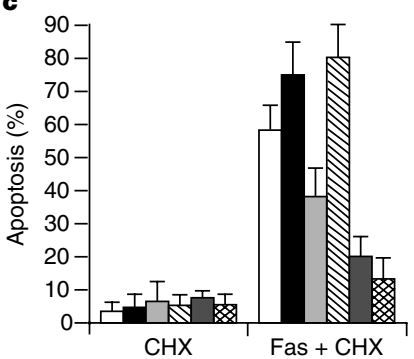

d

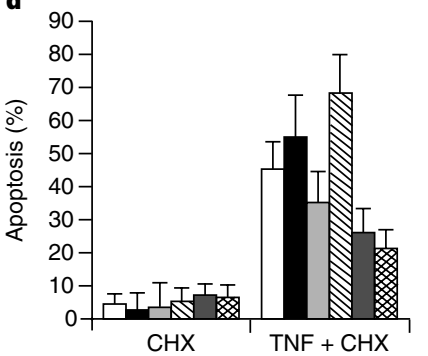

e

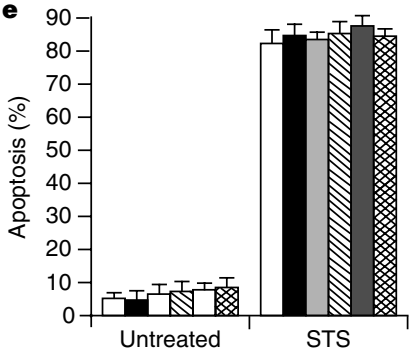

$\mathbf{f}$

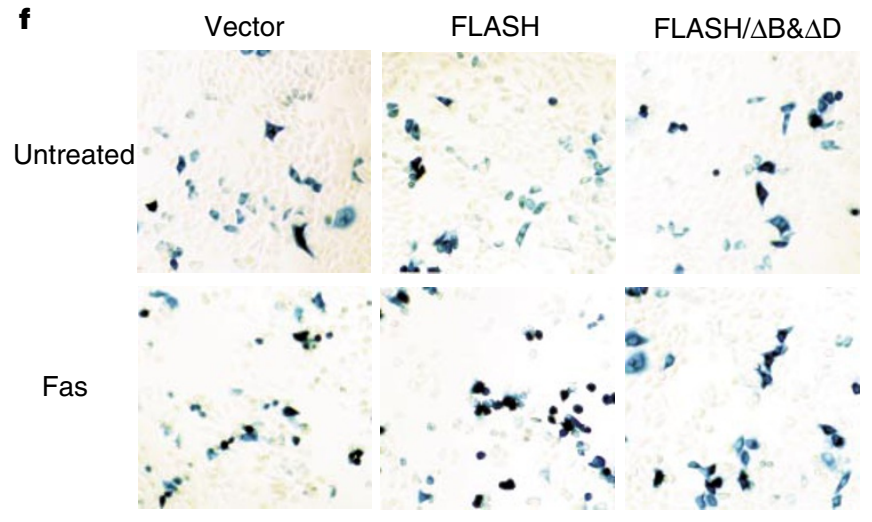

Figure 5 Effects of transfected FLASH and its mutants on activation of caspase-8 and Fas-induced apoptosis. a, Effects of FLASH on cleavage-associated activation of caspase-8. Human 293Fas cells were transiently transfected with pME18S, or pME18S-Flag-FLASH or -FLASH/DD, and then treated with $\mathrm{CH} 11$ $\left(2 \mu \mathrm{g} \mathrm{ml}^{-1}\right)$ for the indicated times. Total lysates from $10^{6}$ cells were analysed by immunoblotting with anti-caspase-8 mAb. Migration positions of full-length (ProCasp-8), cleaved intermediate ( $\mathrm{p} 43$; doublet) and the activated large subunit (p18) of caspase-8 are indicated. $\mathbf{b}$, Expression of transfected FLASH and its mutants in 293Fas cells. Total cellular lysates of $293 \mathrm{Fas}$ cells ( $10^{5}$ cells per sample) transiently transfected with pME18S (lane 1), or pME18S-Flag-FLASH (lane 2), or pME18SFlag-FLASH $/ \Delta \mathrm{D}$ (lane 3) were immunoblotted using anti-Flag mAb. c-e, Effects of FLASH on apoptosis mediated by anti-Fas antibody $\mathrm{CH} 11$ (c), TNF (d) and STS (e). HF1 cells were transfected with control vector, Flag-FLASH-encoding vector, or vectors harbouring deletion mutants of FLASH together with pJ7-LacZ, and were then treated with $\mathrm{CH}-11\left(0.1 \mathrm{~g} \mathrm{ml}^{-1}\right)$ and cycloheximide $\left(10 \mu \mathrm{g} \mathrm{ml}^{-1}\right)$, TNF $\left(0.1 \mathrm{\mu g} \mathrm{ml}^{-1}\right)$ and cycloheximide $\left(10 \mu \mathrm{g} \mathrm{ml}^{-1}\right)$ or STS $(1 \mu \mathrm{M})$ for $6 \mathrm{~h}$. f. Morphology of the stained cells in $\mathbf{c}$. Cells transfected with the indicated plasmids were treated either with (lower) or without (upper) $\mathrm{CH} 11$. CHX, cycloheximide. 
I cells) than in hepatocyte (type II cells) (Fig. 2). The difference between type I and type II cells ${ }^{24}$, however, could not be explained by endogenous expression of caspase- 8 and FLASH, given that the expression of these proteins is similar in type I SKW6.4 cells and in type II Jurkat cells, although there is slightly less FADD in the latter (Fig. 4b). Recruitment of FADD to Fas after and even before stimulation of Fas is more likely in type I SKW6.4 cells than in type II Jurkat cells (Fig. 4b). These results suggest that recruitment of FADD can cause sufficient DISC formation in type I cells, although it is possible that recruitment of the FLASH-caspase- 8 complex to Fas-FADD complex is dominant.

We found that a portion of FLASH transiently transfected into mammalian cells could be proteolytically cleaved without Fas stimulation (Fig. 4a, lane 7). We suspected that overexpressed FLASH could be processed by caspase- 8 activated in a Fas-independent manner, because the cleaved products of FLASH disappeared from cells treated with the caspase inhibitor Z-VAD-fmk (a general caspase inhibitor) or Z-IETD-fmk (a caspase-8-like caspase inhibitor), but not Ac-DEVD-CHO (a caspase-3-like caspase inhibitor) (data not shown). There are potential cleavage sites for caspase in FLASH and putative NLSs are present in the C-terminal region, suggesting that cleaved C-terminal FLASH with the DRD domain might translocate to the nucleus following caspase activation. The cleavage products of FLASH may have a role in caspasedependent nuclear translocation of apoptotic effectors or signal amplifiers such as CAD/DFF40 and DEDD (refs 20, 32, 33). Alternatively, the processing of FLASH may be a negative-feedback pathway for activating caspase.

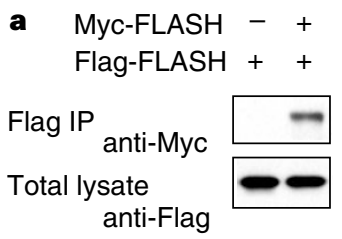

b

$\begin{array}{lllll}\text { Myc-FLASH } & + & + & + & + \\ \text { Flag- } \Delta \mathrm{A} & + & & & \\ \text { Flag- } \Delta \mathrm{C} & & + & & \\ \text { Flag- } \Delta \mathrm{B} & & & + & \\ \text { Flag- } \Delta \mathrm{D} & & & & \end{array}$

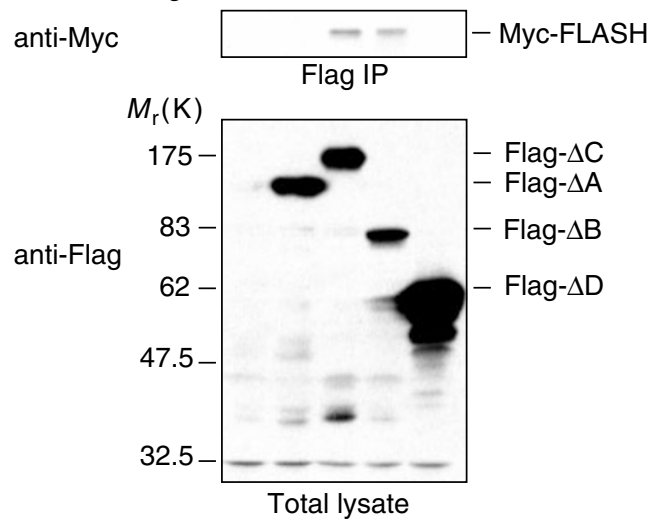

anti-Myc

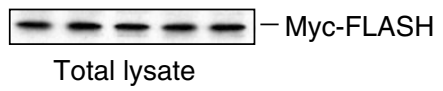

Figure 6 Self-association of FLASH through its CED-4-homologous domain. a, b. Myc-FLASH was expressed in 293T cells with Flag-FLASH (a) or various Flag-tagged deletion mutants of FLASH (see Fig. 1d) (b) in the presence of $20 \mu \mathrm{M}$ Z-VAD-fmk. Myc-FLASH, co-immunoprecipitated with Flag-FLASH or Flagtagged deletion mutants using anti-Flag $m A b$, was detected with anti-Myc mAb 9E10. Expression of Flag-FLASH and Myc-FLASH was determined by western blotting for total-cell lysate with anti-Flag and anti-Myc mAbs, respectively.
FLASH has a Walker's A-box motif for ATP/GTP binding in the CED-4-like domain and is specifically labelled in vitro by $5^{\prime}-p$ fluorosulphonylbenzoyl adenosine, an ATP analogue (data not shown). FLASH has an extra 24 amino acids between the Walker's $\mathrm{A}$ and $\mathrm{B}$ boxes compared with other CED-4-related molecules. In an experiment in which the FLASH ATP/GTP-binding site was disrupted (using an A-box K950R mutant), there was no significant activation of caspase- 8 or apoptosis (data not shown). It is hard to assess the dominant-negative effect of the mutant as both the mutant and full-length FLASH were poorly expressed. The ATP/ GTP requirement of FLASH in vivo therefore remains to be determined.

CED-4 and its mammalian counterpart Apaf-1 activate procaspases by oligomerization through the CED-4 domain, an effect of that is inhibited by binding of CED-9 and the anti-apoptotic Bcl-2 family of proteins, respectively ${ }^{30,31}$. We have shown that FLASH

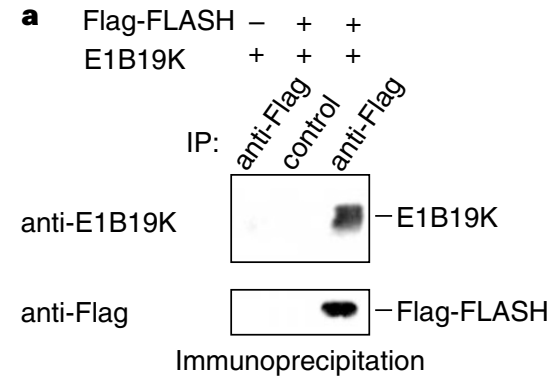

anti-Flag

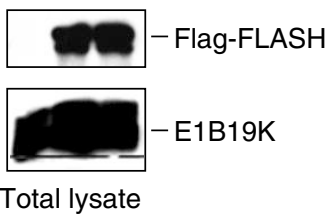

b

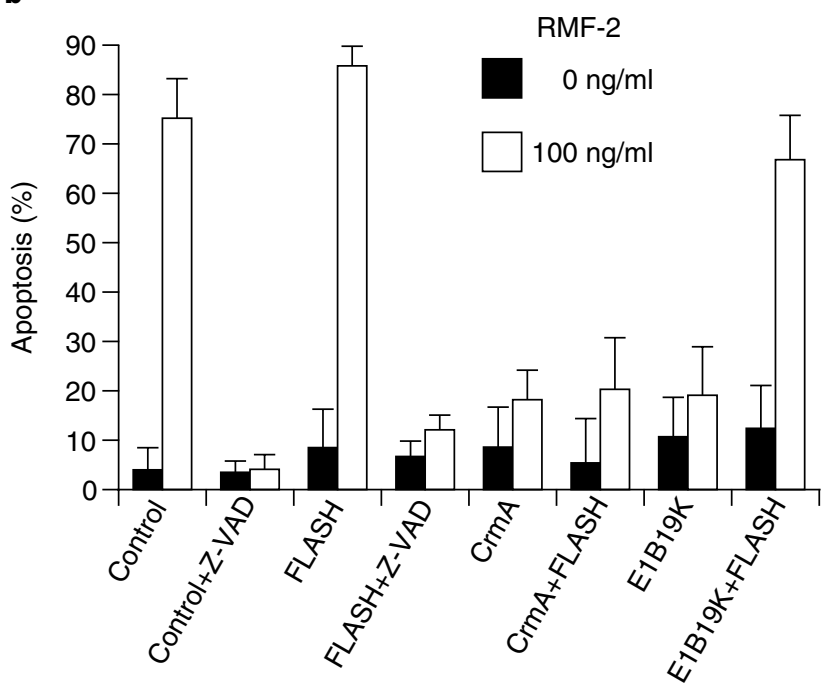

Figure 7 FLASH attenuates the anti-apoptotic effect of adenovirus protein E1B19K. a, Adenovirus E1B19K was expressed in 293T cells with or without FlagFLASH in the presence of $20 \mu \mathrm{M}$ Z-VAD-fmk. Cell lysates were prepared as for Fig. 3a. Co-immunoprecipitated E1B19K was detected by western blotting using anti-E1B19K serum. Expression of Flag-FLASH and E1B19K was determined by western blotting of the total cell lysate with anti-Flag and anti-E1B19K, respectively. b, FH2 cells were transfected with control vector, or expression vectors for CrmA or E1B19K together with Flag-FLASH expression vector or empty vector. Apoptosis was assayed as described in Methods. For analysis using the synthetic peptide inhibitor Z-VAD-fmk (Z-VAD), cells were incubated with $20 \mu \mathrm{M}$ ZVAD-fmk from $30 \mathrm{~min}$ before to $6 \mathrm{~h}$ after Fas stimulation. 
self-associates through its CED-4-homologous domain in the same way as CED-4 and Apaf-1 (Fig. 6). FLASH binds E1B19K, another member of the Bcl-2 family, preventing it from inhibiting Fasmediated apoptosis (Fig. 7). As E1B19K prevents apoptosis induced by FADD as well as by Fas, but not by caspase-8 (ref. 23), it probably works before caspase- 8 is activated and mitochondrial damage is induced by $\mathrm{Bid}^{34-36}$. E1B19K could block formation of the DISC complex by binding to FLASH, and overexpressed FLASH might stop E1B19K binding to the complex of FLASH with caspase-8. FLASH and Bcl-2, both of which are overexpressed in 293T cells, can be co-immunoprecipitated (data not shown), but the significance of this in vivo is unclear as Bcl-2 does not attenuate Fas-mediated activation of caspase- 8 in type I cells ${ }^{24}$. In type II cells, Bcl-2 may inhibit Fas-mediated apoptosis ${ }^{24}$, not only by suppressing Bidinduced mitochondrial damage after caspase- 8 is activated in the DISC complex ${ }^{34-36}$, but also by inhibiting the activation of caspase- 8 as a result of binding to the FLASH-procaspase- 8 complex.

In C. elegans, CED-4 binds to both CED-3 and CED-9 in a complex called the apoptosome $\mathrm{e}^{37,38}$; CED-9 inhibits oligomerization of CED-4 and hence apoptosis ${ }^{30}$. In mammalian systems, CED-4homologous Apaf- 1 binds to procaspase- 9 and cytochrome $c$ (ref. 22); Bcl-2 prevents release of cytochrome $c$ from mitochondria ${ }^{39,40}$ and may bind to Apaf- 1 and inhibit $\mathrm{it}^{41,42}$. The mechanisms of inhibition by CED-9 and Bcl-2 of CED- 4 and Apaf-1, respectively, are therefore different, and in this respect FLASH, which can bind to pro-caspase- 8 and to Bcl-2 family proteins, is like CED-4. Apoptosomes may be genetically conserved in the FLASH system, but the physiological significance of the interaction between FLASH and the Bcl-2 family of proteins is unclear. In conclusion, our results indicate that FLASH has a similar function to CED-4, oligomerizing like CED-4 or Apaf-1 in order to activate procaspase-8.

\section{Methods}

cDNAs, cDNA libraries and antibodies. cDNA fragment of mouse caspase- 8 encoding amino-acid residues 1-202 was generated by PCR using pME18Scaspase- 8 (ref. 43) as template and was cloned into the yeast expression vector pGBT9 (Clontech). Human caspase-8 cDNA (C360S) with a histidine tag was generated by using a Quick-change site-directed mutagenesis kit (Stratagene) and His-tagged human caspase- 8 cDNA, prepared by conventional RT-PCR, as a template and then cloned into the mammalian expression vector pME18S (ref. 44). The random oligonucleotide- and oligo(dT)-primed cDNA libraries for yeast expression screening were prepared from poly $(\mathrm{A})^{+} \mathrm{RNA}$ of the mouse T-cell lymphoma cell line WR19L12a (ref. 1) and the mouse embryonal carcinoma cell line F9 using TimeSaver cDNA synthesis kits (AmershamPharmacia), and inserted into pGAD424.

Anti-human Fas mAb (HFE7A) was freshly prepared. Rabbit polyclonal antibody against mouse FLASH was raised against a 13-mer peptide, LSPNSDRNGDAHR, of FLASH (amino-acid residues 1,843-1,855), and affinity-purified with a deletion mutant of Flag-tagged FLASH $(\triangle \mathrm{D}$ :C-terminal residues $1,553-1,962$ ).

cDNA cloning of FLASH. 5'-RACE PCR combined with nested PCR was performed using a cDNA library of WR19L12a cells in pGAD424 as the template. cDNA libraries of F9 cells were screened using $5^{\prime}$-RACE PCR products encoding amino acids 1-542 and 586-1,012 of FLASH as probes by standard colony hybridization procedures ${ }^{43}$. Five independent clones were sequenced, revealing that these overlapping clones covered the entire coding region of FLASH. Full-length mouse FLASH cDNA was obtained by ligating these clones. cDNA encoding full-length and various deletion mutants of mouse FLASH were cloned into the mammalian expression vector pME18SFlag2, or pME18S-Myc.

Cell lines, transfection and assay of Fas-mediated apoptosis. Human 293 cells stably expressing human Fas (293Fas) and mouse Balb3T3 cell-derived FH2 cells stably expressing transfected mouse Fas were prepared in this laboratory. Cells precultured for 1 day were transfected with various expression vectors using the LipofectAMINE PLUS Reagent (Life Technologies) or cells were transfected by electroporation at 300 volts with a capacitance of $960 \mu \mathrm{F}$ using a Gene Pulser (Bio-Rad). Total amounts of transfected plasmid DNA in individual experiments were adjusted to be the same with the empty vector plasmid. Transfected cells were cultured for at least $24 \mathrm{~h}$ after transfection and were used for immunoprecipitation or induction of Fas-mediated apoptosis.

Human HF1 cells and mouse FH2 cells were transfected with various expression vectors, together with the $\beta$-galactosidase expression vector $\mathrm{pJ} 7$ LacZ. After $24 \mathrm{~h}$ cultivation, HF1 and FH2 cells were stimulated with the human anti-Fas antibody CH11 (ref. 3) in the presence of $10 \mu \mathrm{g} \mathrm{ml}^{-1}$ cycloheximide and anti-mouse Fas monoclonal antibody RFM-2 (ref. 45), respectively. Following incubation for $6 \mathrm{~h}$, cells were fixed with $0.2 \%$ glutaraldehyde and $2 \%$ formaldehyde, and stained with X-Gal for $0.5-1 \mathrm{~h}$. The numbers of blue $\beta$-galactosidase-positive cells with flat adherent morphology and with shrunken round morphology were counted as viable and apoptotic cells, respectively. At least $300 \beta$-galactosidase-positive cells were scored for each transfection in triplicate, and the mean percentages of apoptotic blue cells and their standard errors were calculated.

Immunoprecipitation and western blotting analysis. Cells were lysed in lysis buffer (20 mM HEPES, pH 7.4, $150 \mathrm{mM} \mathrm{NaCl}, 5 \mathrm{mM}$ EDTA, $10 \%$ glycerol, $0.5 \%$ Triton X-100, $1 \mathrm{mM}$ PMSF, $2 \mu \mathrm{g} \mathrm{ml}^{-1}$ aprotinin, $2 \mu \mathrm{g} \mathrm{ml}^{-1}$ leupeptin and $2 \mu \mathrm{g} \mathrm{ml}^{-1}$ pepstatin A). Flag-tagged FLASH was immunoprecipitated from the cell lysate with anti-Flag antibody and protein-G-coupled Sepharose beads (Amersham-Pharmacia), and washed four times with lysis buffer.

Immunoprecipitates or total cell lysates were analysed by western blotting with primary antibodies and horseradish-peroxidase-conjugated second antibodies, and specific bands were detected using chemiluminescence detection reagents (Renaissance; NEN Life Science). To assay the interaction between endogenous FLASH and Fas, WR19L12a cells $\left(2 \times 10^{8}\right)$ were treated with $2 \mu \mathrm{g} \mathrm{ml}^{-1} \mathrm{CH} 11$ for $15 \mathrm{~min}$ at $37^{\circ} \mathrm{C}$ (stimulated sample) or for $30 \mathrm{~min}$ at $4{ }^{\circ} \mathrm{C}$ (unstimulated sample). In SKW6.4 and Jurkat cells $\left(3 \times 10^{9}\right)$, cells $(60 \mathrm{ml})$ were treated with $2 \mu \mathrm{g} \mathrm{ml}^{-1} \mathrm{CH} 11$ for $5 \mathrm{~min}$ at $37^{\circ} \mathrm{C}$ (stimulated sample) or for $30 \mathrm{~min}$ at $4{ }^{\circ} \mathrm{C}$ (unstimulated sample). Treated cells were lysed and immunoprecipitated with anti-human Fas antibody (HFE7A).

For Fig. 3, pME18S-His-caspase-8 (C360S) (His-Casp 8(C360S)) or pME18S-HA-FADD was introduced into 293T cells, together with pME18S encoding Flag-FLASH or Flag-tagged deletion mutants of FLASH (Fig. 1d), or empty pME18S. Transfected cells were cultured for $20 \mathrm{~h}$ and then for $16 \mathrm{~h}$ in the presence of $20 \mu \mathrm{M}$ Z-VAD-fmk (Peptide Institute, Osaka, Japan). Flag-FLASH was immunoprecipitated with anti-Flag mAb M2 (Kodak) from cell lysates containing $1 \mu \mathrm{M}$ Z-VAD-fmk. Co-immunoprecipitated His-Casp 8(C360S) and HA-FADD was detected using anti-His $\mathrm{mAb}^{\mathrm{RGS}}$. His (Qiagen) and anti$\mathrm{HA}$ mAb 12CA5 (Roche Diagnostics), respectively. Total cell lysate was also analysed by western blotting using anti-Flag, anti-His and anti-HA monoclonal antibodies. 293Fas cells were transfected with pME18S-Flag-FLASH. $36 \mathrm{~h}$ later, cells were treated with or without $2 \mu \mathrm{g} \mathrm{ml}^{-1}$ agonistic anti-human Fas mAb CH11 for $15 \mathrm{~min}$. Then, Flag-FLASH was immunoprecipitated from cell lysates using anti-Flag mAb. Co-immunoprecipitated Fas, FADD and caspase- 8 were detected by western blotting analysis using anti-Fas HFE7A, anti-FADD $\mathrm{mAb}$ clone 1 (Transduction Labs) and anti-caspase- 8 mAb 5F7 (MBL, Nagoya, Japan). Immunoprecipitated Flag-FLASH was also detected with anti-Flag $\mathrm{mAb}$.

Received 16 December 1998; accepted 26 March 1999.

1. Itoh, N. et al. The polypeptide encoded by the cDNA for human cell surface antigen Fas can mediate apoptosis. Cell 66, 233-243 (1991).

2. Nagata, S. Apoptosis by death factor. Cell 88, 355-365 (1997).

3. Yonehara, S., Ishii, A. \& Yonehara, M. A cell-killing monoclonal antibody (anti-Fas) to a cell surface antigen co-downregulated with the receptor of tumor necrosis factor. J. Exp. Med. 169, 1747-1756 (1989).

4. Trauth, B. C. et al. Monoclonal antibody-mediated tumor regression by induction of apoptosis. Science 245, 301-305 (1989).

5. Suda, T., Takahashi, T., Golstein, P. \& Nagata, S. Molecular cloning and expression of the Fas ligand, a novel member of the tumor necrosis factor family. Cell 75, 1169-1178 (1993).

6. Chinnaiyan, A. M., O’Rourke, K., Tewari, M. \& Dixit, V. M. FADD, a novel death domain-containing protein, interacts with the death domain of Fas and initiates apoptosis. Cell 81, 505-512 (1995).

7. Boldin, M. P. et al. A novel protein that interacts with the death domain of Fas/APO1 contain a sequence motif related to the death domain. J. Biol. Chem. 270, 7795-7798 (1995).

8. Yeh, W. C. et al. FADD: essential for embryo development and signaling from some, but not all, inducers of apoptosis. Science 279, 1954-1958 (1998).

9. Zhang, J. et al. Fas-mediated apoptosis and activation-induced T-cell proliferation are defective in mice lacking FADD/Mort1. Nature 392, 296-300 (1998)

10. Kischkel, F. C. et al. Cytotoxicity-dependent APO-1 (Fas/CD95)-associated proteins form a deathinducing signaling complex (DISC) with the receptor. EMBO J. 14, 5579-5588 (1995).

11. Boldin, M. P., Goncharov, T. M., Goltsev, Y. V. \& Wallach, D. Involvement of MACH, a novel MORT1/ FADD-interacting protease, in Fas/APO-1- and TNF receptor-induced cell death. Cell 85, 803-815 (1996). 
12. Muzio, M. et al. FLICE, a novel FADD-homologous ICE/CED-3-like protease, is recruited to the CD95 (Fas/APO-1) death-inducing signaling complex. Cell 85, 817-827 (1996).

13. Muzio, M. et al. An induced proximity model for caspase-8 activation. J. Biol. Chem. 273, 2926-2930 (1998).

14. Yang, X., Chang, H. Y. \& Baltimore, D. Autoproteolytic activation of pro-caspases by oligomerization Mol. Cell 1, 319-325 (1998).

15. Enari, M., Talanian, R. V., Wong, W. W. \& Nagata, S. Sequential activation of ICE-like and CPP32-like proteases during Fas-mediated apoptosis. Nature 380, 723-726 (1996).

16. Takahashi, A. et al. Affinity labeling displays the stepwise activation of ICR-related proteases by Fas, staurosporine, and CrmA-sensitive caspase-8. Oncogene 14, 2741-2752 (1997).

17. Fernandes-Alnemri, T., Litwack, G. \& Alnemri, E. S. Mch2, a new member of the apoptotic Ced-3/Ice cysteine protease gene family. Cancer Res. 55, 2737-2742 (1995).

18. Villa, P., Kaufmann, S. H. \& Earnshaw, W. C. Caspases and caspase inhibitors. Trends Biochem. Sci. 22, 388-393 (1997).

19. Rudel, T. \& Bokoch, G. M. Membrane and morphological changes in apoptotic cells regulated by caspase-mediated activation of PAK2. Science 276, 1571-1571 (1997).

20. Enari, M. et al. A caspase-activated DNase that degrades DNA during apoptosis, and its inhibitor ICAD. Nature 391, 43-50 (1998).

21. Chinnaiyan, A. M. et al. Role of CED-4 in the activation of CED-3. Nature 388, 728-729 (1997).

22. Li, P. et al. Cytochrome $\mathrm{c}$ and dATP-dependent formation of Apaf- $1 /$ caspase- 9 complex initiates an apoptotic protease cascade. Cell $91,479-489$ (1997).

23. Perez, D. \& White, E. E1B 19K inhibits Fas-mediated apoptosis through FADD-dependent sequestration of FLICE. J. Cell Biol. 141, 1255-1266 (1998).

24. Scaffidi, C. et al. Two CD95 (APO-1/Fas) signaling pathways. EMBO J. 17, 1675-1687 (1998).

25. Kozak, M. The scanning model for translation: an update. J. Cell Biol. 108, 229-241 (1989).

26. Walker, J. E., Saraste, M., Runswick, M. J. \& Gay, N. J. Distantly related sequences in the alpha- and beta-subunits of ATP synthetase, myosin, kinases and other ATP-requiring enzymes and a common nucleotide binding fold. EMBO J. 1, 945-951 (1982).

27. Nigg, E. A. Nucleocytoplasmic transport: signals, mechanisms and regulation. Nature 386, 779-787 (1997).

28. Wada, A., Fukuda, M., Mishima, M. \& Nishida, E. Nuclear export of actin: a novel mechanism regulating the subcellular localization of a major cytoskeletal protein. $E M B O J .17,1635-1741$ (1998). 29. Medema, J. P. et al. FLICE is activated by association with the CD95 death-inducing signaling complex (DISC). EMBO J. 16, 2794-2804 (1997).

30. Yang, X., Chang, ,H. Y. \& Baltimore,, D. Essential role of CED-4 oligomerization in CED-3 activation and apoptosis. Science 281, 1355-1357 (1998).

31. Srinivasula, S. M., Ahmad, M., Fernandes-Alnemri, T. \& Alnemri, E. S. Autoactivation of procaspase- 9 by Apaf-1-mediated oligomerization. Mol. Cell 1, 949-957 (1998).

32. Liu, X., Zou, H., Slaughter, C. \& Wang, X. DFF, a heterodimeric protein that functions downstream of caspase-3 to trigger DNA fragmentation during apoptosis. Cell 89, 175-184 (1997).
33. Stegh, A. H. et al. DEDD, a novel death effector domain-containing protein, targeted to the nucleolus. EMBO J. 17, 5974-5986 (1998).

34. Medema, J. P., Scaffidi, C., Krammer, P. H. \& Peter, M. E. Bcl-xL acts downstream of caspase-8 activation by the CD95 death-inducing signaling complex. J. Biol. Chem. 273, 3388-3393 (1998).

35. Li, H., Zhu, H., Xu, C. J. \& Yuan, J. Cleavage of BID by caspase 8 mediates the mitochondrial damage in the Fas pathway of apoptosis. Cell 94, 491-501 (1998).

36. Luo, X. et al. Bid, a Bcl2 interacting protein, mediates cytochrome $\mathrm{c}$ release from mitochondria in response to activation of cell surface death receptors. Cell 94, 481-490 (1998).

37. Chinnaiyan, A. M., O'Rourke, K., Lane, B. R. \& Dixit, V. M. Interaction of CED-4 with CED-3 and CED-9: a molecular framework for cell death. Science 275, 1122-1126 (1997).

38. Hengartner, M. O. Apoptosis. CED-4 is a stranger no more. Nature 388, 714-715 (1997).

39. Yang, J. et al. Prevention of apoptosis by Bcl-2: release of cytochrome $\mathrm{c}$ from mitochondria blocked. Science 275, 1129-1132 (1997).

40. Kluck, R. M., Bossy-Wetzel, E., Green, D. R. \& Newmeyer, D. D. The release of cytochrome c from mitochondria: a primary site for Bcl-2 regulation of apoptosis. Science 275, 1132-1136 (1997).

41. Pan, G., O'Rourke, K. \& Dixit, V. M. Caspase-9, Bcl-XL, and Apaf-1 form a ternary complex. J. Biol. Chem. 273, 5841-5845 (1998).

42. Hu, Y. et al. Bcl-XL interacts with Apaf-1 and inhibits Apaf-1-dependent caspase-9 activation. Proc. Natl Acad. Sci. USA 95, 4386-4391 (1998)

43. Sakamaki, K., Tsukumo, S. \& Yonehara, S. Molecular cloning and characterization of mouse caspase8. Eur. J. Biochem. 253, 399-405 (1998).

44. Sakamaki, K., Miyajima, I., Kitamura, T. \& Miyajima, A. Critical cytoplasmic domains of the common beta subunit of the human GM- CSF, IL-3 and IL-5 receptors for growth signal transduction and tyrosine phosphorylation. EMBO J. 11, 3541-3549 (1992).

45. Nishimura, Y. et al. Expression and function of mouse Fas antigen on immature and mature T cells. J. Immunol. 154, 4395-4403 (1995).

46. Eberstadt, M. et al. NMR structure and mutagenesis of the FADD (Mort1) death-effector domain. Nature 392, 941-945 (1998)

47. van der Biezen, E. A. \& Jones, J. D. The NB-ARC domain: a novel signaling motif shared by plant resistance gene products and regulators of cell death in animals. Curr. Biol. 8, R226-227 (1998).

48. Yonehara, S. et al. Involvement of apoptosis antigen Fas in clonal deletion of human thymocytes. Int. Immunol. 6, 1849-1856 (1994).

Acknowledgements. We thank Y. Tsujimoto for cDNAs encoding Bcl-2 and SKW6.4 cells, D. V. Goeddel for mouse FADD cDNA, D. J. Pickup for CrmA cDNA, S. Hashimoto for antiserum against E1B19K, S. Tsukumo for pME18S-Flag2, H. Kazama for pME18S-Myc and FH2 cells, and Y. Nakanishi for HF1 cells. This work was supported in part by a Grant-in-Aid from the Ministry of Education, Science, Sports and Culture of Japan, and by the Ministry of Health and Welfare, Japan.

Correspondence and requests for materials should be addressed to S.Y. (e-mail: syonehar@virus.kyoto-u. ac.jp). 
24. Current Protocols in Molecular Biology (eds Ausubel, F et al) (Wiley, New York, 1989).

25. Rueter, S. M., Burns, C. M., Coode, S. A., Mookherjee, P. \& Emeson, R. B. Glutamate receptor RNA editing in vitro by enzymatic conversion of adenosine to inosine. Science 267, 1491-1494 (1995).

26. Emeson, R. B., Hedjran, F., Yeakley, J. M., Guise, J. W. \& Rosenfeld, M. G. Alternative production of calcitonin and CGRP mRNA is regulated at the calcitonin-specific splice acceptor. Nature 341, 76-80 (1989)

27. Kunkel, T. A. Rapid and efficient site-specific mutagenesis without phenotypic selection. Proc. Natl Acad. Sci. USA 82, 488-492 (1985).

Acknowledgements. We thank J. Barnett, J. Patton, B. Wadzinski, C. Desai and members of R.B.E.'s laboratory for critically reading this manuscript. This work was supported by a grant from the NIH

Correspondence and requests for materials should be addressed to R.B.E. (e-mail: ron.emeson@mcmail. vanderbilt.edu).

\section{Structural basis for initiation of transcription from an RNA polymerase-promoter complex}

\section{Graham M. T. Cheetham ${ }^{\star} \dagger$, David Jeruzalmi ${ }^{\star} \ddagger$ \& Thomas A Steitz ${ }^{\star} \dagger$}

Departments of ${ }^{\star}$ Molecular Biophysics and Biochemistry and $\$$ Chemistry and the $\dagger$ Howard Hughes Medical Institute, Yale University, 266 Whitney Avenue, New Haven, Connecticut 06520-8114, USA

Although the single-polypeptide-chain RNA polymerase from bacteriophage T7 (T7RNAP), like other RNA polymerases, uses the same mechanism of polymerization as the DNA polymerases, it can also recognize a specific promoter sequence, initiate new RNA chains from a single nucleotide, abortively cycle the synthesis of short transcripts, be regulated by a transcription inhibitor, and terminate transcription ${ }^{1-3}$. As T7RNAP is homologous to the Pol I family of DNA polymerases ${ }^{4}$, the differences between the structure of T7RNAP complexed to substrates and that of the corresponding DNA polymerase complex provides a structural basis for understanding many of these functional differences. T7RNAP initiates RNA synthesis at promoter sequences that are conserved from positions -17 to +6 relative to the start site of transcription. The crystal structure at $2.4 \AA$ A resolution of T7RNAP complexed with a 17-base-pair promoter shows that the four base pairs closest to the catalytic active site have melted to form a transcription bubble. The $\mathrm{T} 7$ promoter sequence is recognized by interactions in the major groove between an antiparallel $\beta$-loop and bases. The amino-terminal domain is involved in promoter recognition and DNA melting. We have also used homology modelling of the priming and incoming nucleoside triphosphates from the T7 DNA-polymerase ternary complex structure to explain the specificity of T7RNAP for ribonucleotides, its ability to initiate from a single nucleotide, and the abortive cycling at the initiation of transcription.

T7RNAP has a relative molecular mass of 99,000 $\left(M_{\mathrm{r}}=99 \mathrm{~K}\right)$ and is homologous to the RNA polymerases from the T3 and SP6 phages $^{5,6}$, as well as the nuclear-encoded mitochondrial RNA polymerases from fungi, plants and animals ${ }^{7}$. Hydroxyl radical footprinting of the initiation phase of RNA synthesis reveals an extension of DNA protection by T7RNAP downstream from the promoter with no change in upstream protection ${ }^{8}$, a phenomenon explained either by protein expansion ('inchworming') or DNA contraction ('scrunching'). In this initiation phase, the RNA polymerase can abort synthesis of the transcript before entering the elongation phase, resulting in short transcripts (abortive cycling) ${ }^{2}$. The relative simplicity of T7RNAP makes it an attractive polymerase to study ${ }^{9,10}$

We co-crystallized T7RNAP with a blunt-ended, 17-base-pair

$\$$ Present address: Laboratory of Molecular Biophysics, The Rockefeller University, 1230 York Avenue New York, New York 10021, USA. (bp) promoter DNA (sequence given in Fig. 1). The structure of the complex was determined at $2.4 \AA$ resolution by multiple isomorphous replacement, using selenomethionyl-substituted protein and iodo-containing oligonucleotides, and a mercury acetate derivative. The coordinates of the complex have been refined to yield an $R_{\text {free }}$ value of 0.27 (Table 1).

T7RNAP and other members of the DNA-polymerase I family have modular structures, with auxiliary domains and motifs specific to each polymerase attached to the catalytic core domain ${ }^{11}$. The 324residue $\mathrm{N}$-terminal domain of T7RNAP, which is unique to the RNA-polymerase members of the Pol-I family, blocks part of the active-site cleft $^{9}$ which binds primer-template product in DNA polymerases. Thirteen base pairs (positions -17 to -5 ) of the T7 promoter are bound to this $\mathrm{N}$-terminal domain in a position away from the location of primer-template DNA seen in DNA polymerases $^{12,13}$. Base pairs -1 to -4 are melted by T7RNAP and the template strand is directed into the catalytic active-site cleft of the polymerase.

Sequence-specific recognition of the duplex promoter by T7RNAP is accomplished by a combination of direct and indirect readout in adjacent major and minor grooves, respectively (Fig. 2a). Direct base-recognition is achieved by an anti-parallel $\beta$-ribbon that is inserted into the DNA major groove. Most DNA-protein complexes perform sequence-specific recognition of bases by inserting an $\alpha$-helix, present in a variety of motifs, into the major groove of Bform $\mathrm{DNA}^{14}$; however, sequence recognition by antiparallel $\beta$ strands is far less common ${ }^{15,17}$.

Although, in principle, up to six amino-acid positions can be presented by antiparallel $\beta$-strands for interaction with the exposed edges of base pairs ${ }^{18}$, T7RNAP uses four side-chains lying on one side of an extended antiparallel $\beta$-hairpin motif, or specificity loop (residues 739-770). These form the basis for discrimination between T7 promoter and other DNA sequences. In contrast to other Pol-I polymerases, this specificity loop is an insertion between the polymerase fingers and palm subdomains and exhibits no known homology to other sequence-dependent DNA-binding motifs.

The T7, T3 and SP6 RNA polymerases are a homologous family of enzymes that recognize and discriminate among similarly homologous but different promoter sequences. This is accomplished mainly by the four protein side chains that interact with four

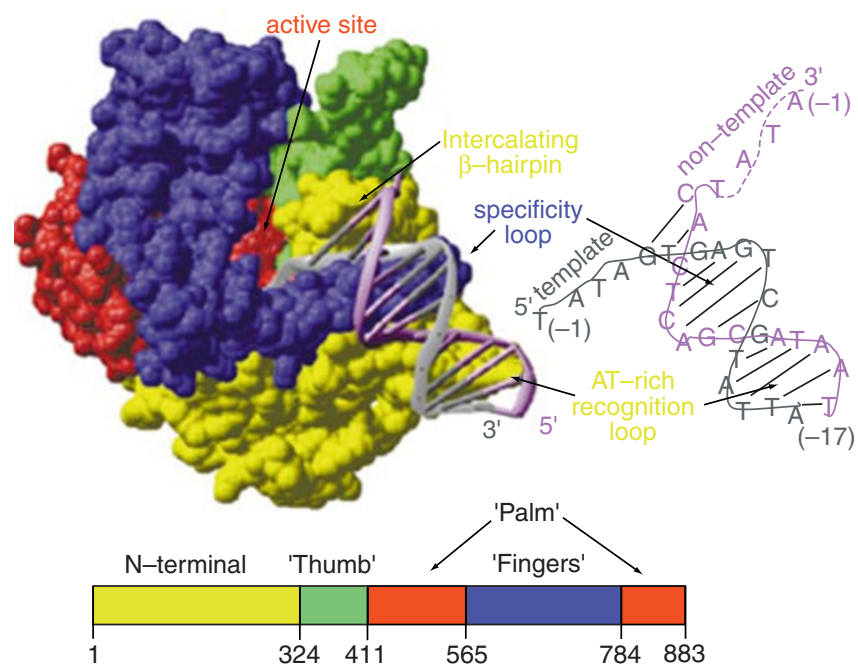

Figure 1 Surface representation of the T7RNAP-promoter complex structure. In all figures, the polymerase subdomains are coloured red 'palm', green 'thumb' and blue 'fingers'. The N-terminal domain which is specific to all phage-like RNA polymerases is yellow, and the template and non-template strands are shown in grey and magenta, respectively. The sequence of the promoter and sequence organization of the T7RNAP domains are also given. 
bases. The guanidinium group of Arg 756 interacts with the 6-keto and 7-imino groups of G-9, while Gln 758 and Arg 746 make bidentate hydrogen-bonds with A-8 and G-7, respectively (Fig. $2 \mathrm{~b})$. The only major groove interactions with bases of the nontemplate strand are made by Asn 748, which directly hydrogenbonds to N7 and indirectly interacts through a water-mediated hydrogen bond to the 6-keto group of G-11. These interactions are essential for recognition of the T7 promoter; mutation of Asn 748 to Asp makes T7RNAP specific for T3 promoters ${ }^{5}$, explaining why the T3 enzyme has Asp at this position. Similarly, the primary discrimination elements of the SP6 promoter are base pairs at -8 and -9 (ref. 6). The Asp 748 mutant of T7RNAP can recognize the T3 promoter by forming an alternative hydrogen-bonding network with C-11 (non-template) and G-10 (template), and by relocating the water molecule within the protein-DNA interface. The bidentate interaction of Arg 756 and Gln 758 with the template strand at positions A-8 and G-9 accounts for the inability of T7RNAP specifically to recognize and use SP6 promoters, which have thymine and cytosine at these positions. The recognition residues in the SP6 enzyme corresponding to 756 and 758 are lysine and

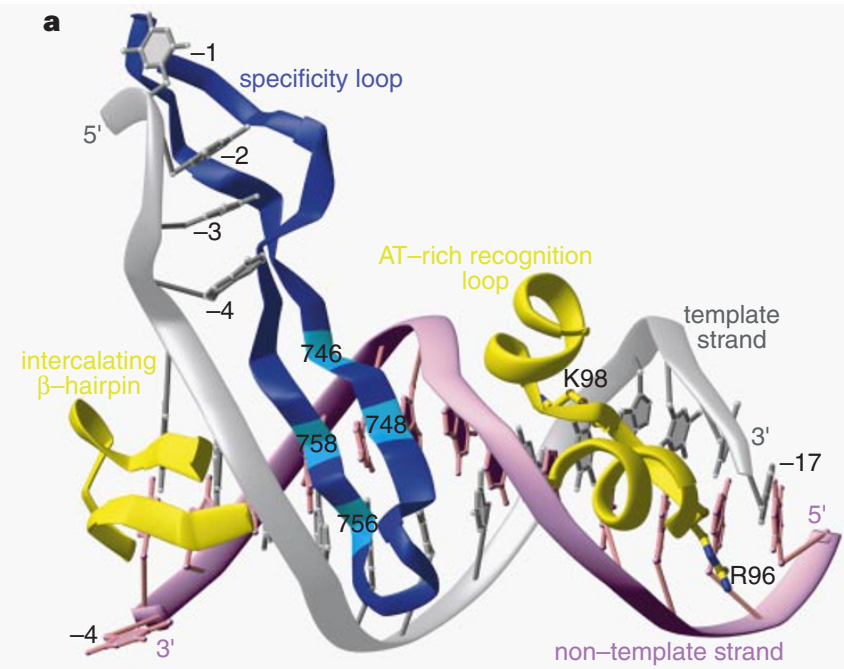

c

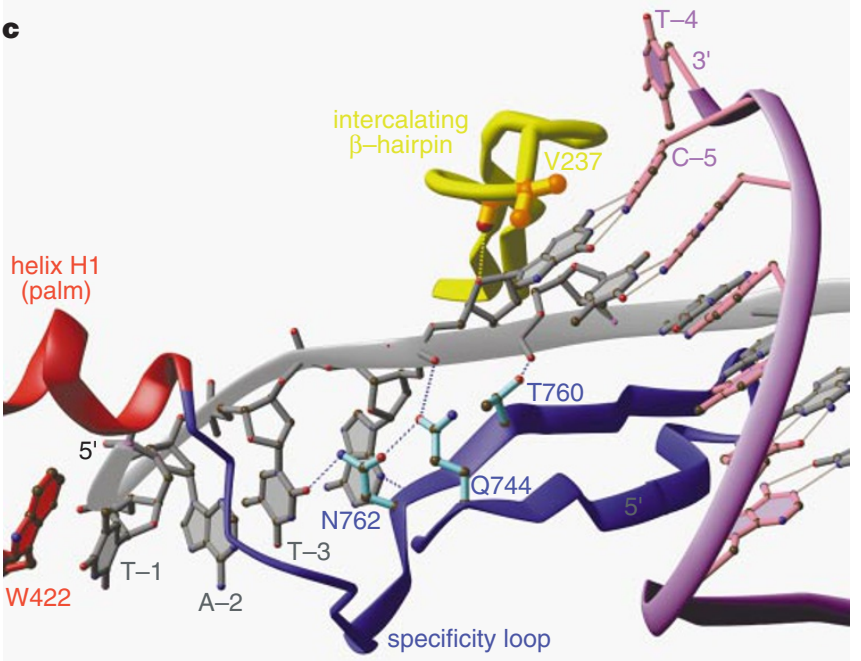

Figure 2 Interactions between the T7-promoter DNA and three regions of T7RNAP that are unique to the RNA polymerase. $\mathbf{a}$, Two loops from the N-terminal domain and one from the fingers interact with the promoter. The side chains of Arg 96 and Lys 98 located in the N-terminal AT-rich minor-groove-recognition loop are shown in detail, and the $\mathrm{C} \alpha$ positions of the four side chains that interact in the major groove are indicated. $\mathbf{b}$, Sequence-specific hydrogen-bonding interactions between protein side chains and bases in the major groove of the promoter. A serine.

The N-terminal domain of T7RNAP indirectly recognizes the DNA sequence in the minor groove at base pairs -17 to -13 by inserting a flexible surface loop, or AT-rich recognition loop (residues 93-101), into the minor groove (Fig. 2a). At the same time, the phosphodiester backbone is distorted to form a wider ( $7 \AA$ versus $5.7 \AA$ ) and shallower $(4.4 \AA$ versus $7.5 \AA$ ) minor groove, compared to B-form DNA. Thus, T7RNAP may recognize the $\mathrm{A}+\mathrm{T}$-rich sequence through its inherent flexibility ${ }^{14}$. These distortions cause a slight bend in the axis of the DNA helix. However, compared to the DNA distortion produced by eukaryotic TATAbinding proteins ${ }^{19,20}$, unwinding of the double helix at these positions by T7RNAP is minimal.

The N-terminal domain also facilitates melting of the promoter duplex, both by inserting a $\beta$-hairpin containing Val 237 in place of base pair -4 to stack on base pair -5 , and by providing an extensive binding site for the melted template strand (Fig. 2c). The packing of this $\beta$-hairpin containing Val 237 is also presumably essential for the maintenance of the upstream part of the bubble during the elongation phase of transcription. An analogous denaturation of duplex

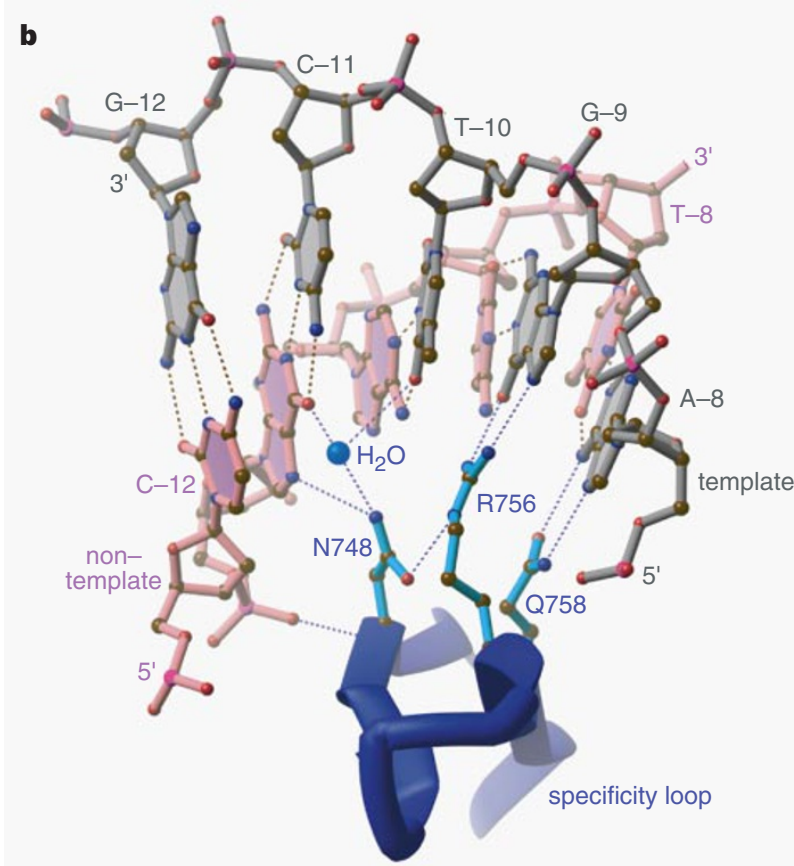

bound water molecule is part of the polymerase-DNA interface, as are the three side chains shown. c, Formation of the upstream transcription bubble facilitated by duplex disruption and template binding. Residue Val 237 separates the template and non-template strands and redirects the exposed template towards the catalytic active site. The $5^{\prime}$ terminus of the template strand (position -1 ) is anchored in a pocket at the junctions of the palm, fingers and $\mathrm{N}$-terminal domains by a base-stacking interaction with residue Trp 422. 
RNA occurs in the complex between tRNA ${ }^{\text {Gln }}$ and Gln-tRNA synthetase, where Leu 136 stacks on G2-C71 and melts base pair U1-A72 (ref. 21).

The promoter is further stabilized in an open conformation by interactions between the single-stranded portion of the template strand and residues belonging to the specificity loop (Fig. 2c). These interactions are mostly confined to the phosphodiester backbone, consistent with the need for sequence-independent binding of the template strand during translocation. The aromatic side chain of Trp 422 stacks on the -1 base, inducing a sharp bend in the template strand, which orients the base at position +1 for initiating ribonucleotides.

Because the T7 RNA and DNA polymerases are homologous enzymes of the Pol-I family, the structure of the DNA polymerase complexed with primer-template and $\mathrm{dGTP}^{13}$ can be used to model by homology the +1 to +3 template strand as well as the priming and incoming ribonucleoside triphosphates onto the T7RNAP. To align the two polymerases, $17 \alpha$-carbon atoms from the three $\beta$ strands in the polymerase palm domains containing the conserved carboxylates in each enzyme were superimposed with a root-meansquare deviation (r.m.s.d.) of $0.67 \AA$. We assumed that the substrates bind to both polymerases identically, and transferred five nucleotides at the primer terminus of the DNA-polymerase complex to the T7RNAP (Fig. 3). This produced a model for the +1 to +3 template nucleotides, the priming GTP and the incoming GTP. The $\beta$ - and $\alpha-$ phosphates of the priming GTP were positioned to make plausible interactions with the T7RNAP protein.

The homology-modelled initiation complex fits well onto the T7RNAP promoter complex, with no steric clashes; it explains many of the functional properties of T7RNAP. The surface topology of the RNA polymerase exactly accommodates the +1 to +3 nucleotides of the template strand in the conformation observed in the DNA polymerase (Fig. 3), supporting the idea that these two enzymes bind this portion of the template in the same way. The two $\mathrm{Mg}^{2+}$ ions and the incoming nucleoside triphosphate are positioned next to the catalytic carboxylates in exactly the same way in both enzymes. Perhaps the strongest support for this model is the distance of $1.4 \AA$ between the terminal $5^{\prime}$ phosphate (position -1) in the RNA polymerase co-crystal structure and the $\mathrm{O}^{\prime}$ ribose position $(+1)$ homology modelled from the T7DNAP complex, without any optimization of their relative positions.

The model suggests two reasons why T7RNAP can initiate

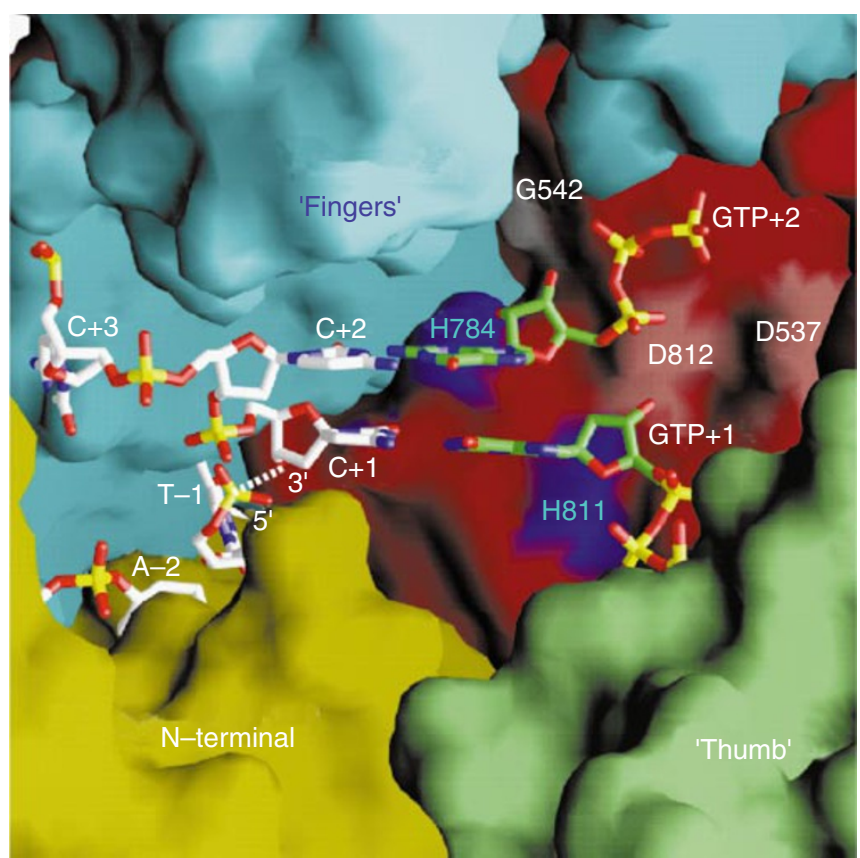

Figure 3 Homology-modelled initiation complex. A surface representation of the active-site cleft of T7RNAP. Nucleotides -2 and -1 of the T7RNAP template strand observed in this complex, the homology-model-built priming $(+1)$ and incoming (+2) GTPs and the complementary template strand (+1 to +3) derived from the T7 DNA-polymerase ternary complex structure ${ }^{13}$ are shown in detail. The areas of histidine residues 784 and 811 are coloured cyan, residue Gly 542 is grey, and residues Asp 812 and Asp 537 are shown in pink.

synthesis from a single priming nucleotide, whereas the DNA polymerase cannot. First, as a result of the specific promoter binding, the RNA polymerase exactly positions the template strand in the active site, providing important complementary base-pairing sites for the bases of the priming and incoming nucleoside triphosphates at the +1 and +2 positions, unlike a single-stranded DNA bound at DNA-polymerase active sites. Second, there is an additional interaction between the 2 '-hydroxyl of the priming nucleotide and the RNA polymerase that would further stabilize the positioning of this nucleotide. The N $\delta 1$ posi-

Table 1 Summary of crystallographic analysis

\begin{tabular}{|c|c|c|c|c|c|}
\hline & Native & $\mathrm{Hgl}$ & lodine I & lodine II & SeMet \\
\hline Wavelength $(\AA)$ & 0.92 & 1.5418 & 1.5418 & 0.92 & 0.979 \\
\hline Resolution (Å) & 2.4 & 3.4 & 3.8 & 4.0 & 3.2 \\
\hline Completness & 96.7 & 91.3 & 85.3 & 91.4 & 79.0 \\
\hline R sym (I )* & 0.08 & 0.12 & 0.12 & 0.07 & 0.08 \\
\hline No. of sites & & $5 \mathrm{Hg}+2 \mathrm{l}$ & 1 & 2 & 22 \\
\hline$R_{\text {iso }}(F) \dagger$ & & 0.32 & 0.17 & 0.25 & 0.18 \\
\hline Phasing power & & 1.21 & 0.67 & 0.84 & 1.03 \\
\hline
\end{tabular}

acentric datał

Solvent-flattening density modification

$\begin{array}{ll}\text { MIRAS F.O.m.§ all data } & 0.83 \\ \text { SOLO F.o.m. all data } & 0.86\end{array}$

Structure refinement $(40-2.4 \AA)$

Resolution ( $\AA$ )

No. reflections working/free

$R / R_{\text {freel }} \| 40-2.40 \AA$ (outer bin $2.45-2.40 \AA$ )

r.m.s. d. (bond), (angle) $\uparrow$

No. protein residues/nucleotides/water

$\begin{array}{llll}10.0 & 7.0 & 5.5 & 4.8 \\ 0.7 & 0.7 & 0.7\end{array}$

$\begin{array}{lll}0.7 & 0.7 & 0.7\end{array}$

$0.8 \quad 0.8$

0.61

$0.9 \quad 0.8$

0.8

0.8

40-2.4F>3 $(F)$

$45,066 / 5,011$

$0.22(0.32) / 0.27(0.37)$

$0.009 \AA, 1.47^{\circ}$

862 (missing residues $1-5,56-71$ )/31 (missing non-template -1 to -3 )/450

$\left.{ }^{*} R_{\mathrm{sym}}=||-\langle\rangle\right\rangle \mid /$, where $/$ is the observed intensity and \langle\rangle$\rangle$ is the average intensity for multiple observations of symmetry related reflections.

t Mean fractional isomorphous difference $=\Sigma|| F$ ph ||$F p|||| F p \mid$ where $|F p|$ is the protein structure factor amplitude and $\mid F$ ph| is the heavy-atom structure factor amplitude.

$\neq$ Phasing power $=$ r.m.s. $(|F p h| \mid E)$, where $E$ is the residual lack of closure.

$\S$ F.o.m., figure of merit.

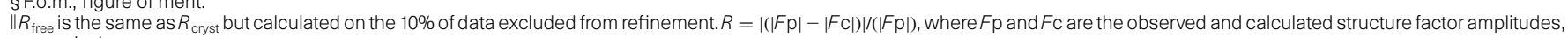
respectively.

$\uparrow$ Root-mean-squared deviation given from ideal values. 
tion of His 811 , which is implicated in ribonucleotide binding and phosphodiester-bond formation ${ }^{22}$, is ideally positioned to hydrogen-bond with the $2^{\prime}$-OH of the priming GTP. This interaction also assures initiation by ribo rather than deoxyribonucleotides.

T7RNAP can incorporate ribonucleotides in preference to deoxyribonucleotides because of His 784 and Gly 542. The discrimination of DNA polymerases against ribonucleotides has been proposed ${ }^{23}$ to result from these enzymes presenting a 'steric gate' to the incoming nucleotide; the steric gate is a bulky residue that overlaps the position that would be occupied by the $2^{\prime}-\mathrm{OH}$ of a ribonucleotide. In most DNA polymerases of the Pol-I family, this residue is a glutamic acid (residue 710 in the Klenow fragment). The corresponding homologous residue in T7RNAP is Gly542, allowing room for a $2^{\prime}-\mathrm{OH}$. T7RNAP discriminates against a deoxy substrate partly by providing His 784 to hydrogen-bond to the $2^{\prime}-\mathrm{OH}$; desolvating His 784 in the absence of the $2^{\prime}-\mathrm{OH}$, leaving a hole, would be energetically costly. Both Gly 542 and His 784 are absolutely conserved in all phage-like DNA-dependent RNA polymerases.

This co-crystal structure indicates that the abortive cycling that occurs at the initiation of transcription requires accumulation of the DNA template strand at the polymerase active site. The extent of promoter protection from hydroxyl-radical hydrolysis produced by methidiumpropyl-EDTA.Fe(II) in the presence of T7RNA polymerase at various early stages in the elongation reaction has been determined $^{8}$. Although protection of the downstream DNA sequences extended as the open complex was formed and RNA was synthesized, the extent of protection of the upstream sequences did not change. At least two models can explain how the polymerase can expand its downstream protection of the DNA while maintaining the upstream protection- 'protein inchworming' and 'DNA scrunching'. The protein-inchworming model suggests that the duplex recognition portion of the enzyme and the polymerase portion of the enzyme reside on different domains and can move independently of each other as RNA synthesis proceeds. The DNAscrunching model keeps the enzyme structure constant but requires that the template and non-template DNA strands can be accommodated progressively in the polymerase active site as synthesis proceeds; the single-stranded DNA is compacted or 'bunched' near the synthesis site. The synthesis active site and the promoterbinding region cannot move relative to each other because the antiparallel $\beta$-ribbon that is recognizing the promoter DNA comes from the 'fingers' domain, which also provides part of the binding site for the incoming nucleoside triphosphate. We propose that, during the abortive initiation phase of RNA synthesis, the template strand accumulates in the active site while the promoter duplex is still bound to the protein.

\section{Methods}

We purified T7RNAP as described ${ }^{9}$ from Escherischia coli strain BL21(DE3) containing plasmid pAR1219 (ref. 24). The selenomethionyl enzyme was produced in E. coli strain B834(DE3) and purified under strict reducing conditions. For crystallization, duplex T7 DNA promoters, made by annealing trityl-purified (Vydac $\mathrm{C}_{4}$ reversed-phase column) synthetic oligonucleotides, were mixed with T7RNAP in a 1.3:1 ratio at a concentration of $30 \mathrm{mg} \mathrm{ml}^{-1}$ and $\mathrm{pH}$ 7.8. We obtained very thin plate-like crystals, which diffract to $2.4 \AA$ resolution at the CHESS F1 beamline, by vapour diffusion of the complex mixed with an equal volume of the well solution against a well solution containing $20 \%$ PEG $8000 \mathrm{~K}, 200 \mathrm{mM}$ ammonium sulphate, $0.25 \% \beta$-octyl glucopyranoside and $100 \mathrm{mM}$ Tris- $\mathrm{HCl}, \mathrm{pH}$ 8.7. Derivatives were prepared either by adding heavy-atom reagents to the crystallization drop or by using modified DNA oligonucleotides in crystallization, and diffraction data were collected at $100 \mathrm{~K}-110 \mathrm{~K}$ using crystals that had been stabilized by addition of $16 \%$ propylene glycol before flash-freezing in liquid propane. We reduced the intensity data using MOSFLM $^{25}, \mathrm{DENZO}^{26}$ and the CCP4 program suite ${ }^{27}$ to reveal a unit cell of dimensions $a=220.1, b=73.3, c=161.9 \AA$ and space group $P 2{ }_{1} 2_{1} 2_{1}$. However, subsequent analysis of these data revealed a systematic distribution of weak intensities for reciprocal lattice with planes odd values of $l$, resulting from the two molecules in the crystallographic asymmetric unit being separated by a translation corresponding to almost exactly $c / 2$. As the mean $I / \sigma(I)=1.3$, for all odd values of $l$ data, further analyses were performed in a unit cell with one half the $c$ dimension and one molecule per asymmetric unit. Reducing the number of parameters by 2 proved more useful than including the extremely weak reflections. Initial experimental phases calculated by multiple isomorphous replacement with anomalous scattering with the program MLPHARE $^{27}$ gave readily interpretable electron-density maps only after phase extension from $3.6 \AA$ to $2.8 \AA$ resolution using solvent-flattening density-modification $\left(\right.$ Program Solomon ${ }^{28}$ ). Iterative cycles of model rebuilding ${ }^{29}$ and refinement ${ }^{30}$ were performed, initially incorporating experimental phase information in electron-density-map calculation and model-refinement restraints. Individual $B$-factors were refined and a bulk solvent correction was applied. Coordinates have been deposited in the Protein Data Bank (accession number 1ClZ).

Received 23 December 1998; accepted 9 March 1999.

1. Steitz, T. A., Smerdon, S. J., Jaeger, J. \& Joyce, C. M. A unified polymerase mechanism for nonhomologous DNA and RNA polymerase. Science 266, 2022-2025 (1994).

2. Carpousis, A. J. \& Gralla, J. D. Cycling of ribonucleic acid polymerase to produce oligonucleotides during initiation in vitro at the lac UV5 promoter. Biochemistry 19, 3245-3253 (1980).

3. McAllister, W. T. \& Wu, H.-L. Regulation of transcription of the late genes of bacteriophage T7. Proc. Natl Acad. Sci. USA 75, 804-808 (1978).

4. Delarue, M., Poch, O., Tordo, N., Moras, D. \& Argos, P. An attempt to unify the structure of polymerases. Protein Eng. 3, 461-467 (1990).

5. Raskin, C. A., Diaz, G., Joho, K. \& McAllister, W. T. Substitution of a single bacteriophage T3 residue in bacteriophage T7 RNA polymerase at position 748 results in a switch in promoter specificity. J. Mol. Biol. 228, 506-515 (1992).

6. Lee, S. S. \& Kang, C. A two base-pair substitution in T7 promoters by SP6 promoter-specific base-pairs alone abolishes T7 promoter activity but reveals SP6 promoter activity. Biochem. Int. 26, 1-5 (1992).

7. Masters, B. S., Stohl, L. L. \& Clayton, D. A. Yeast mitochondrial RNA polymerase is homologous to those encoded by bacteriophage T3 and T7. Cell 51, 89-99 (1987).

8. Ikeda, R. A. \& Richardson, C. C. Interactions of the RNA polymerase of bacteriophage T7 with its promoter during binding and initiation of transcription. Proc. Natl Acad. Sci. USA 83, 3614-3618 (1986).

9. Jeruzalmi, D. \& Steitz, T. A. Structure of the T7 RNA polymerase complexed to the transcriptional inhibitor T7 lysozyme. EMBO J. 17, 4101-4113 (1998).

10. Souza, R., Chung, Y. J., Rose, J. P. \& Wang, B.-C. Crystal structure of bacteriophage T7 RNA polymerase at $3.3 \AA$ resolution. Nature 364, 595-599 (1993).

11. Steitz, T. A. DNA- and RNA-dependent DNA polymerases. Curr. Opin. Struct. Biol. 3, 31-38 (1993).

12. Eom, S. H., Wang, J. \& Steitz, T. A. Structure of Taq polymerase with DNA at the polymerase active site. Nature 382, 278-281 (1996).

13. Doublié, S., Tabor, S., Long, A. M., Richardson, C. C. \& Ellenberger, T. Crystal structure of a bacteriophage T7 DNA replication complex at $2.2 \AA$ resolution. Nature 391, 251-258 (1998).

14. Steitz, T. A. Structural studies of protein-nucleic acid interactions: The sources of sequence specific binding. Q. Rev. Biophys. 23, 205-280 (1990).

15. Rice, P. A., Yang, S., Mizuuchi, K. \& Nash, H. A. Crystal structure of an IHF-DNA complex: A protein induced DNA U-turn. Cell 87, 1295-1306 (1996).

16. Somers, W. S. \& Phillips, S. E. V. Crystal structure of the met repressor-operator complex at $2.8 \AA$ resolution reveals DNA recognition by $\beta$-strands. Nature 359, 387-393 (1992).

17. Raumann, B. E., Rould, M. A., Pabo, C. O. \& Sauer, R. T. DNA recognition by beta-sheets in the Arc repressor-operator crystal structure. Nature 367, 754-757 (1994).

18. Suzuki, M. DNA recognition by a $\beta$-sheet. Protein Eng. 8, 1-4 (1995).

19. Kim, Y., Geiger, J. H., Hahn, S. \& Sigler, P. B. Crystal structure of a yeast TBP/TATA-box complex. Nature 365, 512-520 (1993).

20. Kim, J. L., Nikolov, D. B. \& Burley, S. K. Co-crystal structure of TBP recognizing the minor groove of a TATA element. Nature 365, 520-527 (1993).

21. Rould, M. A. \& Steitz, T. A. Structure of the glutaminyl-tRNA synthetase-tRNA ${ }^{\text {Glu }}$-ATP complex. Nucleic Acids Mol. Biol. 6, 225-245 (1992).

22. Osumi-Davis, P. A., Aguilera, M. C., Woody, R. W. \& Woody, A. Y. M. Asp 357, Asp 812 are essential and Lys 631, His 811 are catalytically significant in bacteriophage T7 RNA polymerase activity. J. Mol. Biol. 226, 37-45 (1992).

23. Gao, G., Orlova, M., Georgiadis, M. M., Hendrickson, W. A. \& Goff, S. P. Conferring RNA polymerase activity to a DNA polymerase: A single residue in reverse transcriptase controls substrate selection. Proc. Natl Acad. Sci. USA 94, 407-411 (1997).

24. Davanloo, P., Rosenberg, A. H., Dunn, J. J. \& Studier, F. W. Cloning and expression of the gene for bacteriophage T7 RNA polymerase. Proc. Natl Acad. Sci. USA 81, 2035-2039 (1984).

25. Leslie, A. G. W. Joint CCP4 and ESF-EACMB Newsletter Protein crystallogr. No. 26 (Daresbury Laboratory, Warrington, UK, 1992).

26. Otwinowski, Z. \& Minor, W. Processing of X-ray diffraction data collected in oscillation mode. Methods Enzymol. 276, 307-326 (1997).

27. Collaborative Computational Project No. 4. The CCP4 Suite: Programs for protein crystallography. Acta Crystallogr. D 50, 760-763 (1994).

28. Abrahams, J. P. \& Leslie, A. G. W. Methods used in the structure determination of bovine mitochondrial F1 ATPase. Acta Crystallogr. D 52, 30-42 (1996).

29. Jones, T. A., Zou, J. Y., Cowan, S. W. \& Kjeldgaard, M. Improved methods for building protein models in electron density maps and the location of errors in these models. Acta Crystallogr. A 47, 110-119 (1991).

30. Brünger, A. T. et al. Crystallography and NMR system: A new software suite for macromolecular structure determination. Acta Crystallogr. D 54, 905-921 (1998).

Acknowledgements. We thank many members of the T.A.S. laboratory for assistance with data collection at beamlines X12C (NSLS, Brookhaven Laboratory), Al, F1 and F2 (Cornell High Energy Synchrotron). This work was supported by a grant from the N.I.H.

Correspondence and requests for materials should be addressed to T.A.S. 